Review Article

\title{
Predictive and Prognostic Role of PD-L1 in Urothelial Carcinoma Patients with Anti-PD-1/PD-L1 Therapy: A Systematic Review and Meta-Analysis
}

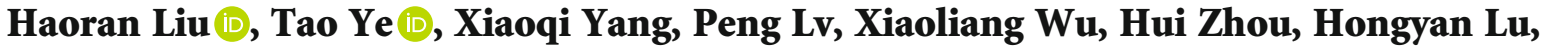 \\ Kun Tang $\oplus$, and Zhangqun Ye \\ Department of Urology, Tongji Hospital, Tongji Medical College, Huazhong University of Science and Technology, \\ Wuhan 430030, China \\ Correspondence should be addressed to Kun Tang; tangsk1990@163.com
}

Received 2 August 2019; Accepted 24 December 2019; Published 27 June 2020

Academic Editor: Eric A. Singer

Copyright (C) 2020 Haoran Liu et al. This is an open access article distributed under the Creative Commons Attribution License, which permits unrestricted use, distribution, and reproduction in any medium, provided the original work is properly cited.

Recently, checkpoint inhibition of the PD-1/PD-L1 axis has been shown to be therapeutically relevant in urothelial carcinoma (UC). To evaluate the predictive and prognostic value of PD-L1 on response and survival in UC patients after cystectomy, chemotherapy, or anti-PD-1/PD-L1 therapy, a systematic review of PubMed, Embase, Web of Science, and the Cochrane Library was performed. A total of 2154 patients from 14 published studies were included. In all UC patients after cystectomy, tumour cell (TC) PD-L1 expression was not associated with the OS or PFS. For the subset of patients with organ-confined disease, TC PD-L1 expression significantly predicted OS after cystectomy $(P=0.0004)$. There was no significant evidence of an association between TC PD-L1 status and ORR or OS for UC patients treated with platinum-based chemotherapy. For UC patients treated with anti-PD-1/PD-L1 therapy, TC PD-L1 expression $\geq 5 \%$ could predict the response $(P=0.005)$, but not for the $1 \%$ cut-off $(P \geq 0.05)$. As for PD-L1 expression in tumour-inflating immune cells (TIICs), both subsets with IC2/3 vs. IC0/1 and IC1/2/3 vs. IC0 were associated with ORR to anti-PD-1/PD-L1 therapy. In the TIIC subset, IC2/3 vs. IC0/1 of PD-L1 was associated with higher CR $(P=0.002)$, PR $(P=0.04)$, and PD $(P=0.007)$. Further, higher TIIC PD-L1 status benefited from longer PFS $(P<0.001)$, but was not associated with OS in UC patients with anti-PD-1/PD-L1 therapy. Our study suggested that TIIC PD-L1 expression with 5\% cut-off was valuable as a predictive and prognostic biomarker for ORR and PFS in UC patients with anti-PD-1/PD-L1 therapy.

\section{Introduction}

Urothelial carcinoma (UC) is regarded as an aggressive tumour, with unfavorable clinical survival in advanced stages and metastatic diseases. Radical cystectomy (RC) is the goldstandard treatment for muscle-invasive organ-confined UC, providing efficacy of local control and better disease-free survival (DFS) [1, 2]. With high expression level of programmed death-ligand 1 (PD-L1), UC appears to be immunogenic, demonstrating the potential value of PD-L1 as a promising biomarker in UC after RC [3]. Although the upregulated PD-L1 was associated with tumour-infiltrating immune cell (TIIC) response and advanced disease, clinical efficiency for
UC patient survival was characterized by different degrees of uncertainty [4].

Patients with metastatic UC usually had a poor prognosis; perioperative cisplatin-based chemotherapy in addition to RC could benefit a response of $50 \%$ and prolong survival [5]. However, Tsao and colleagues performed a meta-analysis raising serious doubt about the predictive value of PD-L1 expression in prognosis and response for adjuvant chemotherapy in early stage non-small cell lung cancer (NSCLC). They indicated that PD-L1 status showed neither prognostic nor predictive value of benefits from adjuvant chemotherapy in patients with partial pneumonectomy [6]. Therefore, it remained contentious whether 


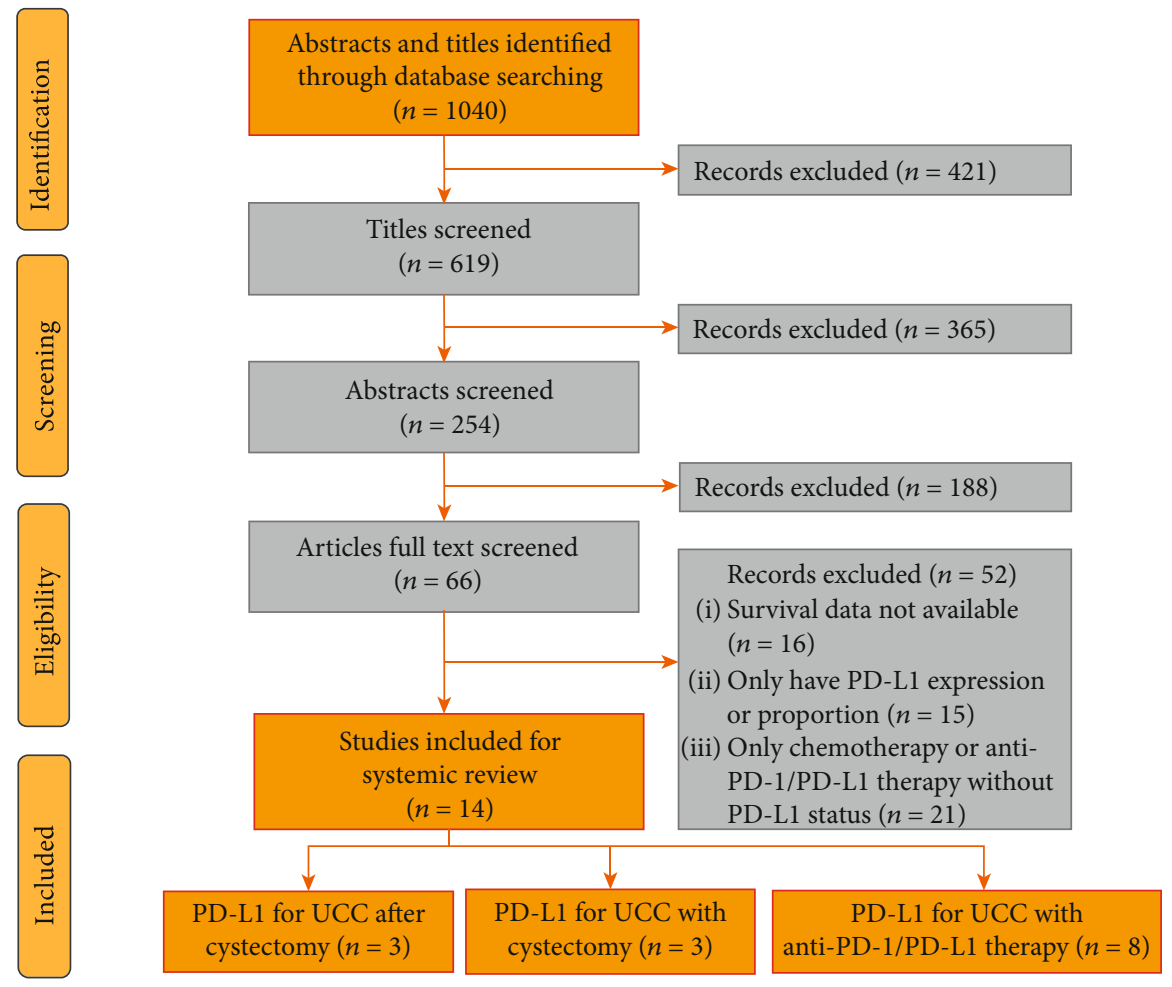

Figure 1: Flow diagram for study selection.

PD-L1 could serve as a valuable biomarker in UC patients with adjuvant chemotherapy.

Recently, blocking immune checkpoints with anti-PD1/PD-L1 monoclonal antibodies has demonstrated promising clinical efficacy for advanced UC [7]. The effect of PD-1 on T-cells with its ligand PD-L1 on tumour cell and immune cell interaction inhibited the function of effector T-cells [8]; therefore, tumours could escape from $\mathrm{T}$-cell regulated immune response by blocking the PD-1/PD-L1 signaling pathway [9]. PD-1/PD-L1 inhibitors have shown survival benefits in various advanced cancers, including melanoma, lymphoma, NSCLC, renal cell carcinoma, and UC [9-12]. PD-L1 status has been demonstrated to significantly correlate with response and survival improvement from antiPD-1/PD-L1 immunotherapy in UC patients [13], while there is no convincing evidence whether PD-L1 expression in tumour cells (TCs) or TIICs with a cut-off value of $5 \%$ or $1 \%$ could predict the prognosis and response.

To clarify the available evidence, we conducted this metaanalysis of eligible literatures to determine the predictive and prognostic significance of PD-L1 expression in UC patients receiving cystectomy, chemotherapy, or anti-PD-1/PD-L1 immunotherapy.

\section{Material and Methods}

2.1. Search Strategy. All methods for this systematic review and meta-analysis are outlined in a prospectively registered protocol available online (PROSPERO identifier CRD42019130411). Our meta-analysis was performed following the Preferred Reporting Items for Systematic
Reviews and Meta-Analyses (PRISMA) guidelines [14]. Studies published before January 2019 were electronically retrieved from the PubMed, Web of Science, Embase, and Cochrane Library databases. The following terms were used: urothelial carcinoma or urothelial tumour or urothelial neoplasm or bladder cancer or bladder tumour; PD-L1 or programmed cell death ligand 1 or $\mathrm{B} 7-\mathrm{H} 1$ or CD274. The reference lists were also screened to obtain other eligible studies by correspondence with study investigators. Each study was evaluated independently by two reviewers for the inclusion. Any disagreement in the articles was resolved by discussing with a third reviewer. Figure 1 shows the flow diagram of the study selection.

2.2. Selection Criteria. Included publications should satisfy the following criteria: (1) The studies reported PD-L1 expression on urothelial carcinoma. (2) The results showed the association of PD-L1 status and any of the following outcomes: objective response rate, PFS or OS after cystectomy, and chemotherapy or anti-PD-1/PD-L1 immunotherapy. (3) Only clinical trials, including prospective or retrospective cohort studies or comparative series, were eventually enrolled. Exclusion criteria were the following: (1) studies only reported the PD-L1 expression in urothelial carcinoma patients; (2) studies only studied the molecular mechanism of PD-L1 and its biological function in bladder cancer; (3) animal or in vitro studies; (4) studies did not report or no data available on response rate, PFS, or OS; and (5) articles not in English, case reports, comments, letters, editorials, congress reports, and review papers. When several papers from the same center were 
TABLE 1: Characteristics of the included studies on PD-L1 status predicting the prognosis in UC patients after cystectomy.

\begin{tabular}{|c|c|c|c|}
\hline Study & Boorjian et al. (2008) [4] & Wang et al. (2009) [18] & Xylinas et al. (2014) [19] \\
\hline Country & USA & China & USA \\
\hline Study interval & 1990-1994 & $2000-2002$ & $1988-2003$ \\
\hline Age (years) & $69(37-90)$ & $62(42-78)$ & $66(61-72)$ \\
\hline Male/female & $259 / 59$ & $40 / 10$ & $244 / 58$ \\
\hline Management & $\mathrm{RC}$ & $\mathrm{RC}$ & $\mathrm{RC}$ \\
\hline PD-L1 expression & Tumour cells & Tumour cells & Tumour cells \\
\hline Detection method & IHC & IHC & IHC \\
\hline Cut-off value & $5 \%$ & $10 \%$ & $5 \%$ \\
\hline Follow-up (mons.) & $164(1-210)$ & $28(6-52)$ & $120(78-125)$ \\
\hline Clinical outcomes & $\begin{array}{l}\text { Receipt of BCG, } \\
\text { tumour stage, TIL }\end{array}$ & $\begin{array}{l}\text { Tumour grade, tumour } \\
\text { stage, recurrent UC }\end{array}$ & None* \\
\hline \multicolumn{4}{|l|}{ All UC patients } \\
\hline PD-L1+ & $12.4 \%$ & $72.0 \%$ & $25.2 \%$ \\
\hline $\mathrm{PD}-\mathrm{L} 1+/-$ & $39 / 275$ & $36 / 14$ & $76 / 226$ \\
\hline OS, $\operatorname{HR}(95 \% \mathrm{CI})$ & $1.06(0.71-1.58)$ & $2.24(1.16-4.38)$ & $0.98(0.73-1.31)$ \\
\hline$P$ value & 0.88 & 0.01 & 0.79 \\
\hline CSS, HR(95\% CI) & $0.82(0.42-1.63)$ & na & $0.79(0.53-1.61)$ \\
\hline$P$ value & 0.23 & na & 0.58 \\
\hline DFS, HR(95\% CI) & $0.83(0.43-1.58)$ & na & $0.74(0.50-1.11)$ \\
\hline$P$ value & 0.15 & na & 0.56 \\
\hline Organ-confined disease & & na & \\
\hline $\mathrm{PD}-\mathrm{L} 1+$ & $16.2 \%$ & na & $25.0 \%$ \\
\hline $\mathrm{PD}-\mathrm{L} 1+/-$ & $27 / 140$ & na & $24 / 72$ \\
\hline OS, $\operatorname{HR}(95 \% \mathrm{CI})$ & $2.18(1.26-3.77)$ & na & $1.93(1.09-3.43)$ \\
\hline$P$ value & 0.02 & na & 0.005 \\
\hline CSS, HR(95\% CI) & $1.59(0.56-4.49)$ & na & $1.21(0.47-3.13)$ \\
\hline$P$ value & 0.68 & na & 0.38 \\
\hline DFS, HR(95\% CI) & $1.24(0.44-3.45)$ & na & $1.27(0.50-3.26)$ \\
\hline$P$ value & 0.62 & na & 0.69 \\
\hline
\end{tabular}

UC: urothelial carcinoma; PD-L1: programmed death-ligand 1; +/-: positive/negative; RC: radical cystectomy; TIL: tumour-inflating lymphocyte; IHC: immunohistochemistry; BCG: Bacillus Calmette-Guerin; OS: overall survival; CSS: cancer-specific survival; DFS: disease-free survival; HR: hazard ratio; CI: confidence interval; na: data not available. ${ }^{*}$ No association of PD-L1 expression with clinicopathologic features.

available, the one with the newest information, the longest follow-up, and the most participants was finally included in our meta-analysis.

2.3. Data Extraction and Study Quality. The following data was extracted independently by two trained reviewers (TK and LHR) using a prior-designed form: last name of authors; publication year; study design; country; participants' inclusion and exclusion criteria; mean or median age of participants; sample size; tumour stage; PD-L1 status; assigned to treatment with cystectomy, chemotherapy, or anti-PD-1/PD-L1 immunotherapy; length of follow-up; and primary endpoints including response rate, PFS, and OS. Missing, unclear, but important supplementary data were requested from primary study authors. All discrepancies were adjudicated by a third reviewer and solved by discussion (YZQ). RevMan software version 5.3. (Cochrane, London, UK) was used to perform risk of bias graph and summary.
2.4. Statistical Analysis. All data analysis was conducted using RevMan software version 5.3. Efficacy data from assigned patients were calculated on an intention-to-treat basis in all enrolled studies [15]. The concerned endpoints included the response rates, PFS, and OS. In terms of both OS and PFS, the pooled HRs and their 95\% CI were calculated. A subgroup analysis was performed for patients receiving anti-PD-1/PD-L1 immunotherapy by PD-L1 cut-off value (IC2/3 vs. IC $0 / 1$ or IC1/2/3 vs. IC0). Statistical heterogeneity was quantified by the $Q$ and $I^{2}$ tests. Based on the absence or presence of interstudy heterogeneity, pooled odds ratio (OR) and hazard ratio (HR) estimates were obtained by use of a fixed or random effects model. $P$ values $<0.05$ indicated statistical significance.

\section{Results}

3.1. Baseline Characteristics. Fourteen publications were selected for inclusion; three trials reported the association 
TABLE 2: Characteristics of the included studies on predictive and prognostic value of PD-L1 status in UC patients treated with platinumbased chemotherapy.

\begin{tabular}{lccc}
\hline Study & Baras et al. (2016) [21] & Bellmunt et al. (2015) [3] & Erlmeier et al. (2016) [20] \\
\hline Country & USA & USA & Germany \\
UC patients & MIUC & Metastatic UC & Locally advanced \\
Tumour stage & All stage & pT2-T4 & pT3/pT4 \\
Management & TURBT & TURBT, RC & RC \\
Chemotherapy & Neoadjuvant platinum-based & Adjuvant platinum-based & Adjuvant platinum-based \\
PD-L1 expression & Tumour cells & Tumour cells/TIICs & Tumour cells \\
Detection method & IHC & IHC & IHC \\
Cut-off value & $1 \%, 5 \%$ & $5 \%$ & $10 \%$ \\
PD-L1+ & $20.6 \%$ & $16.3 \%$ & $35.5 \%$ \\
PD-L1+/- & $7 / 34$ & $14 / 86$ & $11 / 31$ \\
ORR (PD-L1+/-) & $42.9 \% / 38.2 \%$ & na & $37.5 \% / 35.7 \%$ \\
OS rate (PD-L1+/-) & na & $64.3 \% / 39.5 \%$ & $54.5 \% / 51.6 \%$ \\
\hline
\end{tabular}

UC: urothelial carcinoma; MIUC: muscle-invasive UC; PD-L1: programmed death-ligand 1; +/-: positive/negative; TURBT: transurethral resection of bladder tumour; RC: radical cystectomy; TIICs: tumour-inflating immune cells; IHC: immunohistochemistry; ORR: objective response rate; OS: overall survival; pT: physical stage; na: data not available.

of PD-L1 status and concerned endpoints in UC patients after cystectomy, three trials reported platinum-based chemotherapy, and eight trials reported anti-PD-1/PD-L1 immunotherapy (Figure 1). All the included studies detected PD-L1 expression by immunohistochemistry (IHC), eight studies only detected the PD-L1 expression in tumour cells (TCs), four trials only in tumour-inflating immune cells (TIICs), and two studies measured PD-L1 in both locations. Three studies recruited UC patients after cystectomy, and one study was excluded without reporting survival HR value and 95\% CI [16]. Two of three studies evaluated PD-L1 expression both in all UC patients and organ-confined disease. Three studies reported OS, and two showed CSS and DFS (Table 1). The baseline characteristics of three studies that reported chemotherapy are outlined in Table 2, and all three studies were about platinum-based preoperative treatment. For patients receiving anti-PD-1/PD-L1 immunotherapy, most of the published trials set $1 \%$ or $5 \%$ as the cut-off value, and one study was excluded with a cut-off value of $25 \%$ [17]. Among the eight trials, only one study was prospective but nonrandomized, and the others were multicenter RCTs. Four studies used atezolizumab, two used nivolumab, one used avelumab, and one used pembrolizumab. PD-L1-positive proportion has been noted ranging from $10.8 \%$ to $46.2 \%$ (5\% cut-off) and $37.3 \%$ to $81.5 \%$ (1\% cut-off) in UC patients. The ORR to anti-PD-1/PD-L1 immunotherapy in UC patients with PD-L1-positive expression ranged from $26.0 \%$ to $43.3 \%$ (5\% cut-off) and $17.9 \%$ to $30.2 \%$ (1\% cut-off) (Tables 3 and 4 ).

3.2. PD-L1 Expression in TCs Predicted Poor Survival after Cystectomy for Patients with Organ-Confined Tumours (but Not All UC). Three studies considering OS and CSS as the primary endpoints were included $[4,18,19]$. For all patients treated with cystectomy, pooled results indicated that the expression of PD-L1 in TCs was not related with the OS (HR, 1.10; 95\% CI, 0.88-1.38; $P=0.40$; Figure 2(a)), CSS
(HR, 0.80; 95\% CI, 0.57-1.12; $P=0.19$; Figure 2(b)), or PFS (HR, 0.76; 95\% CI, 0.54-1.07; $P=0.12$; Figure 2(c)). However, for organ-confined UC, PD-L1 expression in TCs significantly predicted all-cause mortality (OS) after cystectomy (HR, 2.06; 95\% CI, 1.38-3.06; $P=0.0004$; Figure $3(\mathrm{a})$ ), but was not significant in terms of CSS (HR, 1.37; 95\% CI, 0.68-2.76; $P=0.38$; Figure 3(b)) and DFS (HR, 0.26; 95\% CI, 0.63-2.51; $P=0.52$; Figure 3(c)).

3.3. TC PD-L1 Status Showed No Obvious Relationship with the Prognosis or Response to Platinum-Based Chemotherapy of UC Patients. In terms of the previously described association of PD-L1 expression and clinical outcomes in UC, it was investigated whether pretreatment PD-L1 status could predict the response to chemotherapy from three eligible studies $[3,20,21]$. As shown in Figure 4(a), there was no statistical difference of PD-L1 status in the tumour cell membrane between responders and resistant cases (OR, 1.15; 95\% CI, $0.34-3.88 ; P=0.82)$. Also, the result showed no significant evidence of a relationship with PD-L1 expression and OS (OR, 1.89; 95\% CI, 0.78-4.58; $P=0.16$; Figure 4(b)) for UC patients receiving platinum-based chemotherapy.

3.4. TC PD-L1 Expression Failed to Predict the Response to Anti-PD-1/PD-L1 Immunotherapy in UC Patients. Among the 8 trials, 5 RCTs of elevated TC PD-L1 status predicting response to the $\mathrm{PD}-1 / \mathrm{PD}-\mathrm{L} 1$ blockade therapy were pooled in this meta-analysis [22-26]. TC PD-L1 status with $5 \%$ as the cut-off value could predict the ORR to anti-PD-1/PDL1 immunotherapy in UC patients (Figure 5(b)). TC PD - L $1 \geq 5 \%$ was correlated with higher completed response (CR) (OR, 4.24; 95\% CI, 1.29-13.96; $P=0.02$; Figure 6(a)). Otherwise, TC PD-L1 status with a cut-off value of $5 \%$ but not $1 \%$ failed to predict the partial response (PR), stable disease (SD), or progressive disease (PD) (Figure 6) in UC patients receiving anti-PD-1/PD-L1 immunotherapy. 
TABLE 3: Characteristics of the included studies on predictive and prognostic value of tumour-infiltrating immune cell PD-L1 status in UC patients treated with anti-PD-1/PD-L1 therapy.

\begin{tabular}{|c|c|c|c|c|}
\hline Study & Balar et al. (2017) [13] & Powles et al. (2014) [24] & Rosenberg et al. (2016) [28] & Petrylak et al. (2018) [27] \\
\hline Trial name & IMvigor210 & PCD4989g & NCT02108652 & NCT01375842 \\
\hline Study design & MRCT & MRCT & MRCT & MRCT \\
\hline Trial phase & Phase 2 & Phase 1 & Phase 2 & Phase 1 \\
\hline Study interval & 2014-2015 & 2011-2013 & May 2014-Nov 2014 & Mar 2013-Aug 2015 \\
\hline UC patients & $\begin{array}{l}\text { Locally advanced } \\
\text { and metastatic UC }\end{array}$ & Metastatic UC & $\begin{array}{l}\text { Locally advanced } \\
\text { and metastatic UC }\end{array}$ & Metastatic UC \\
\hline Age (years) & $73(51-92)$ & $65(36-86)$ & $66(32-91)$ & $66(36-89)$ \\
\hline Male/female & $96 / 23$ & $46 / 19$ & $241 / 69$ & $72 / 23$ \\
\hline Immunotherapy & Atezolizumab & Atezolizumab & Atezolizumab & Atezolizumab \\
\hline Target & Anti-PD-L1 & Anti-PD-L1 & Anti-PD-L1 & Anti-PD-L1 \\
\hline Treatment & $1200 \mathrm{mg}$, iv every 3 weeks & $15 \mathrm{mg} / \mathrm{kg}$, iv every 3 weeks & 1200 mg, iv every 3 weeks & $15 \mathrm{mg} / \mathrm{kg}$, iv every 3 weeks \\
\hline PD-L1 expression & TIICs & Tumour cells/TIICs & TIICs & TIICs \\
\hline Detection method & IHC & IHC & IHC & IHC \\
\hline Cut-off value & $1 \%, 5 \%$ & $1 \%, 5 \%$ & $1 \%, 5 \%$ & $5 \%$ \\
\hline PD-L1+ (5\%/1\%) & $67.2 \% / 26.9 \%$ & $81.5 \% / 46.2 \%$ & $66.8 \% / 32.3 \%$ & $52.6 \%$ \\
\hline \multicolumn{5}{|c|}{$\mathrm{PD}-\mathrm{L} 1 \geq 5 \%$ vs. $\mathrm{PD}-\mathrm{L} 1<5 \%$} \\
\hline No. of PD-L1+/- & $32 / 87$ & $30 / 35$ & $100 / 210$ & $50 / 44$ \\
\hline ORR (PD-L1+/-) & $28.1 \% / 20.7 \%$ & $43.3 \% / 11.4 \%$ & $26.0 \% / 9.0 \%$ & $40.0 \% / 11.0 \%$ \\
\hline $\mathrm{CR}(\mathrm{PD}-\mathrm{L} 1+/-)$ & $12.5 \% / 8.0 \%$ & na & $11.0 \% / 1.9 \%$ & $16.0 \% / 2.0 \%$ \\
\hline PR (PD-L1+/-) & $15.6 \% / 12.6 \%$ & na & $15.0 \% / 7.1 \%$ & $24.0 \% / 9.0 \%$ \\
\hline $\mathrm{SD}(\mathrm{PD}-\mathrm{L} 1+/-)$ & na & $26.7 \% / 37.1 \%$ & $16.0 \% / 20.5 \%$ & $18.0 \% / 21.0 \%$ \\
\hline $\mathrm{PD}(\mathrm{PD}-\mathrm{L} 1+/-)$ & na & $26.7 \% / 37.1 \%$ & $44.0 \% / 54.8 \%$ & $34.0 \% / 55.0 \%$ \\
\hline \multicolumn{5}{|c|}{$\mathrm{PD}-\mathrm{L} 1 \geq 1 \%$ vs. $\mathrm{PD}-\mathrm{L} 1<1 \%$} \\
\hline No. of PD-L1+/- & $80 / 39$ & $53 / 12$ & $207 / 103$ & na \\
\hline ORR (PD-L1+/-) & $23.8 \% / 20.5 \%$ & $30.2 \% / 8.3 \%$ & $17.9 \% / 7.8 \%$ & na \\
\hline $\mathrm{CR}(\mathrm{PD}-\mathrm{L} 1+/-)$ & $10.0 \% / 7.7 \%$ & na & $6.3 \% / 1.9 \%$ & na \\
\hline $\mathrm{PR}(\mathrm{PD}-\mathrm{L} 1+/-)$ & $13.8 \% / 12.8 \%$ & na & $11.6 \% / 5.8 \%$ & na \\
\hline $\mathrm{SD}(\mathrm{PD}-\mathrm{L} 1+/-)$ & na & $30.2 \% / 41.7 \%$ & $1.9 \% / 24.3 \%$ & na \\
\hline $\mathrm{PD}(\mathrm{PD}-\mathrm{L} 1+/-)$ & na & $30.2 \% / 41.7 \%$ & $51.7 \% / 50.5 \%$ & na \\
\hline PFS(PD-L1+/-) (mon.) & $4.1 \pm 2.4 / 2.4 \pm 0.6$ & na & $4.0 \pm 0.6 / 2.6 \pm 0.3$ & $5.5(2.7-10.8) / 1.4(1.3-2.7)$ \\
\hline OS rate $(\mathrm{PD}-\mathrm{L} 1+/-)$ & $52 \% / 59 \%$ & na & $48 \% / 30 \%$ & $42 \% / 10 \%$ \\
\hline Follow-up (mons.) & $17.2(0.2-23.5)$ & $4.2(1.1-8.5)$ & $11.7(11.4-12.2)$ & $37.8(0.7-44.4)$ \\
\hline
\end{tabular}

TCs: tumour cells; TIICs: tumour-inflating immune cells; UC: urothelial carcinoma; PD-L1: programmed death-ligand 1; +/-: positive/negative; MRCT: multicenter randomized controlled trial; IHC: immunohistochemistry; ORR: objective response rate; CR: completed response; PR: partial response; SD: stable disease; PD: progressive disease; PFS: progression-free survival; OS: overall survival; na: data not available.

3.5. TIIC PD-L1 Expression Predicted Response to Anti-PD$1 / P D-L 1$ Immunotherapy in UC Patients. Among the 6 trials, 4 RCTs of elevated TIIC PD-L1 status predicting the response to anti-PD-1/PD-L1 immunotherapy were pooled in this meta-analysis $[13,24,26,27]$. Both TIIC PD-L1 status with $\mathrm{IC} 2 / 3$ vs. IC0/1 and $\mathrm{IC} 1 / 2 / 3$ vs. IC0 showed significant relationship with ORR to anti-PD-1/PD-L1 immunotherapy and a higher PD-L1 expression was correlated with a better response (IC2/3 vs. IC0/1: OR, 3.35; 95\% CI, 2.17-5.19; $P<0.001$; Figure 5(a); and IC1/2/3 vs. IC0: OR, 2.10; 95\% CI, 1.18-3.73; $P=0.01$; Figure 5(b)). In the TIIC subset, the positive expression (score of 2-3) versus the negative (score of $0-1$ ) of PD-L1 was correlated with higher CR (OR, 4.21;95\% CI, 1.97-9.02; $P=0.0002$;
Figure 7(a)), PR (OR, 2.16; 95\% CI, 1.24-3.74; $P=0.006$; Figure 7(b)), and PD (OR, 0.59; 95\% CI, 0.40-0.87; $P=$ 0.007 ; Figure $7(\mathrm{~d}))$; however, it could not predict the SD (OR, 0.73; 95\% CI, 0.45-1.19; $P=0.21$; Figure 7(c)). In the subset of IC1/2/3 vs. IC0, results indicated that PD-L1 expression level had no significant association with the CR (OR, 2.17; 95\% CI, 0.80-5.91; $P=0.13$; Figure 7(a)), PR (OR, 1.65; 95\% CI, 0.81-3.37; $P=0.17$; Figure 7(b)), SD (OR, 0.19; 95\% CI, 0.02-1.79; $P=0.15$; Figure 7(c)), or PD (OR, 0.99; 95\% CI, $0.63-1.54 ; P=0.95$; Figure $7(\mathrm{~d}))$.

3.6. TIIC PD-L1 Status Predicted PFS and OS in UC Patients Receiving Anti-PD-1/PD-L1 Immunotherapy. Further, only three trails reported the relationship of TIIC PD-L1 status 
TABLE 4: Characteristics of the included studies on predictive and prognostic value of tumour PD-L1 status in UC patients treated with antiPD-1/PD-L1 therapy.

\begin{tabular}{|c|c|c|c|c|c|}
\hline Study & $\begin{array}{c}\text { Plimack et al. } \\
(2017)[23]\end{array}$ & $\begin{array}{l}\text { Powles et al. } \\
(2014)[24]\end{array}$ & $\begin{array}{l}\text { Sharma et al. } \\
(2016)[25]\end{array}$ & $\begin{array}{l}\text { Sharma et al. } \\
(2017)[26]\end{array}$ & $\begin{array}{l}\text { Patel et al. } \\
\text { (2018) [22] }\end{array}$ \\
\hline Trial name & KEYNOTE-012 & PCD4989g & CheckMate 032 & CheckMate 275 & NCT01772004 \\
\hline Study design & MRCT & MRCT & MRCT & Nonrandomised & MRCT \\
\hline Trial phase & Phase $1 \mathrm{~b}$ & Phase 1 & Phase $1 / 2$ & Phase 2 & Phase 1 \\
\hline Study interval & May 2013-Dec 2013 & 2011-2013 & 2014-2015 & Mar 2015-Oct 2015 & Sept 2014-Mar 2016 \\
\hline UC patients & $\begin{array}{l}\text { Locally advanced } \\
\text { or metastatic UC }\end{array}$ & Metastatic UC & Recurrent metastatic UC & Metastatic UC & $\begin{array}{l}\text { Locally advanced } \\
\text { or metastatic UC }\end{array}$ \\
\hline Age (years) & $70(44-85)$ & $65(36-86)$ & $65.5(31-85)$ & $66(38-90)$ & $68(63-76)$ \\
\hline Male/female & $23 / 10$ & $46 / 19$ & $54 / 24$ & $211 / 59$ & $178 / 71$ \\
\hline Immunotherapy & Pembrolizumab & Atezolizumab & Nivolumab & Nivolumab & Avelumab \\
\hline Target & Anti-PD-1 & Anti-PD-L1 & Anti-PD-1 & Anti-PD-1 & Anti-PD-L1 \\
\hline Treatment & $\begin{array}{l}10 \mathrm{mg} / \mathrm{kg}, \mathrm{iv} \\
\text { every } 2 \text { weeks }\end{array}$ & $\begin{array}{l}15 \mathrm{mg} / \mathrm{kg} \text {, iv } \\
\text { every } 3 \text { weeks }\end{array}$ & $\begin{array}{c}3 \mathrm{mg} / \mathrm{kg} \text {, iv } \\
\text { every } 2 \text { weeks }\end{array}$ & $\begin{array}{c}3 \mathrm{mg} / \mathrm{kg} \text {, iv } \\
\text { every } 2 \text { weeks }\end{array}$ & $\begin{array}{l}10 \mathrm{mg} / \mathrm{kg}, \mathrm{iv} \\
\text { every } 2 \text { weeks }\end{array}$ \\
\hline PD-L1 expression & Tumour cells & Tumour cells/TIICs & Tumour cells & Tumour cells & Tumour cells \\
\hline Detection method & $\mathrm{IHC}$ & $\mathrm{IHC}$ & $\mathrm{IHC}$ & $\mathrm{IHC}$ & $\mathrm{IHC}$ \\
\hline Cut-off value & $1 \%$ & $1 \%, 5 \%$ & $1 \%, 5 \%$ & $1 \%$ & $5 \%$ \\
\hline $\mathrm{PD}-\mathrm{L} 1+(5 \% / 1 \%)$ & $84.0 \%$ & $43.1 \% / 10.8 \%$ & $46.0 \% / 30.6 \%$ & $37.3 \%$ & $33.0 \%$ \\
\hline \multicolumn{6}{|c|}{$\mathrm{PD}-\mathrm{L} 1 \geq 5 \%$ vs. $\mathrm{PD}-\mathrm{L} 1<5 \%$} \\
\hline No. of PD-L1+/- & & $7 / 58$ & $81 / 184$ & na & $63 / 76$ \\
\hline ORR (PD-L1+/-) & na & $28.6 \% / 25.9 \%$ & $28.4 \% / 15.8 \%$ & na & $24 \% / 13 \%$ \\
\hline $\mathrm{CR}(\mathrm{PD}-\mathrm{L} 1+/-)$ & na & na & $4.9 \% / 1.1 \%$ & na & $10 \% / 3 \%$ \\
\hline $\mathrm{PR}(\mathrm{PD}-\mathrm{L} 1+/-)$ & na & na & $23.5 \% / 14.7 \%$ & na & $14 \% / 11 \%$ \\
\hline $\mathrm{SD}(\mathrm{PD}-\mathrm{L} 1+/-)$ & na & $14.3 \% / 34.5 \%$ & $28.4 \% / 20.1 \%$ & na & $29 \% / 20 \%$ \\
\hline $\mathrm{PD}(\mathrm{PD}-\mathrm{L} 1+/-)$ & na & $57.1 \% / 29.3 \%$ & $25.9 \% / 45.1 \%$ & na & $29 \% / 50 \%$ \\
\hline \multicolumn{6}{|c|}{$\mathrm{PD}-\mathrm{L} 1 \geq 1 \%$ vs. $\mathrm{PD}-\mathrm{L} 1<1 \%$} \\
\hline No. of PD-L1+/- & $21 / 4$ & $28 / 37$ & $122 / 143$ & $25 / 42$ & na \\
\hline ORR (PD-L1+/-) & $23.8 \% / 0 \%$ & $28.6 \% / 24.3 \%$ & $23.8 \% / 16.1 \%$ & $24.0 \% / 26.2 \%$ & na \\
\hline $\mathrm{CR}(\mathrm{PD}-\mathrm{L} 1+/-)$ & na & na & $1.6 \% / 0.7 \%$ & $16.0 \% / 2.4 \%$ & na \\
\hline $\mathrm{PR}(\mathrm{PD}-\mathrm{L} 1+/-)$ & na & na & $19.7 \% / 15.4 \%$ & $8.0 \% / 23.8 \%$ & na \\
\hline $\mathrm{SD}(\mathrm{PD}-\mathrm{L} 1+/-)$ & na & $28.6 \% / 35.1 \%$ & $28.7 \% / 17.5 \%$ & $32.0 \% / 26.2 \%$ & na \\
\hline $\mathrm{PD}(\mathrm{PD}-\mathrm{L} 1+/-)$ & na & $35.7 \% / 29.7 \%$ & $30.3 \% / 46.9 \%$ & $32.0 \% / 42.9 \%$ & na \\
\hline PFS(PD-L1+/-) (mon.) & na & na & na & na & $\begin{array}{c}11.9(6.1-18) / \\
6.1(5.9-8)\end{array}$ \\
\hline OS rate $(\mathrm{PD}-\mathrm{L} 1+/-)$ & na & na & na & na & $59 \% / 51 \%$ \\
\hline Follow-up (mons.) & $13(5-23)$ & $4.2(1.1-8.5)$ & $15.2(12.9-16.8)$ & $7.0(3.0-8.8)$ & $9.9(4.3-12.1)$ \\
\hline
\end{tabular}

TCs: tumour cells; TIICs: tumour-inflating immune cells; UC: urothelial carcinoma; PD-L1: programmed death-ligand 1; +/-: positive/negative; MRCT: multicenter randomized controlled trial; IHC: immunohistochemistry; ORR: objective response rate; CR: completed response; PR: partial response; SD: stable disease; PD: progressive disease; PFS: progression-free survival; OS: overall survival; na: data not available.

and prognosis in UC patients receiving anti-PD-1/PD-L1 immunotherapy $[13,27,28]$. As shown in Figure 8, pooled results showed that elevated TIIC PD-L1 expression level benefited from improved PFS (IC2/3 vs. IC0/1: WMD, 2.40; 95\% CI, $0.59-4.21 ; P=0.009$; and $\mathrm{IC} 1 / 2 / 3$ vs. IC0: WMD, 0.39; 95\% CI, 0.29-0.49; $P<0.001$ ), but was not correlated with OS in UC patients.

\section{Discussion}

Currently, this was the first meta-analysis discussing the predictive and prognostic significance of PD-L1 expression in
UC patients treated with cystectomy, chemotherapy, or anti-PD-1/PD-L1 immunotherapy. We confirmed that TC PD-L1 status could predict reduced survival after cystectomy for organ-confined UC patients, but not all UC patients. However, we found that TC PD-L1 expression was neither a predictive biomarker for survival benefit or response to adjuvant platinum-based chemotherapy nor a biomarker for response to anti-PD-1/PD-L1 immunotherapy. At the same time, we demonstrated that higher PD-L1 expression of TIICs but not TCs showed significant relationship with better response to the PD-1/PD-L1 blockade therapy. Furthermore, our results found that immune cell PD-L1 


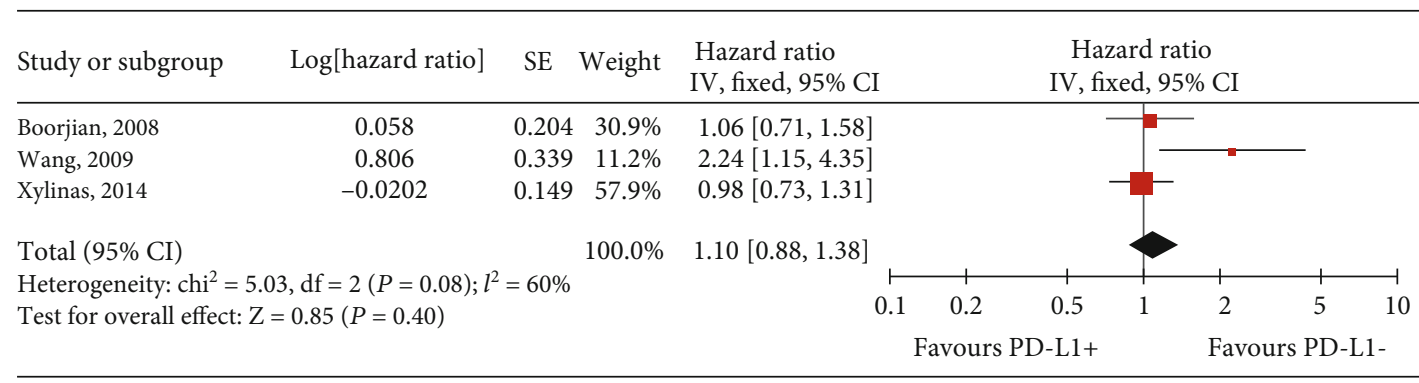

(a)

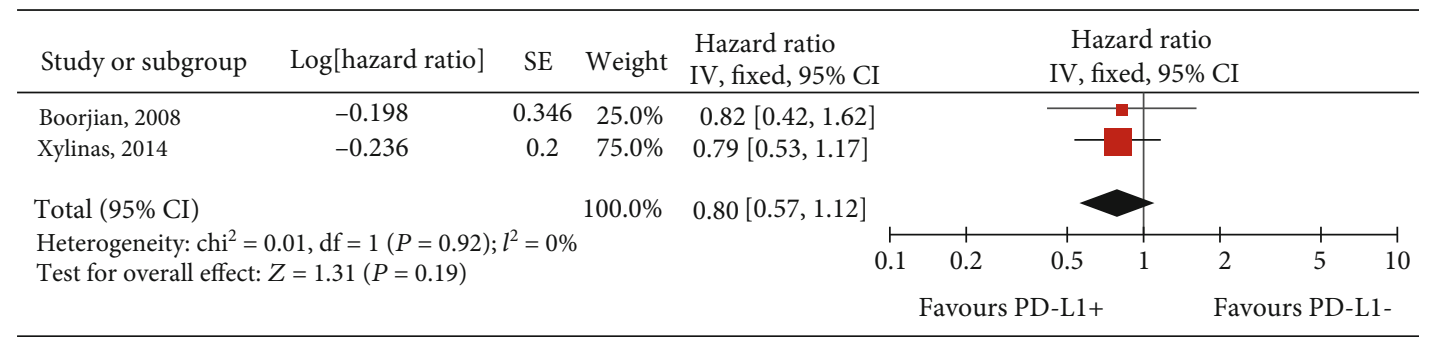

(b)

\begin{tabular}{|c|c|c|c|c|c|c|c|c|}
\hline Study or subgroup & Log[hazard ratio] & SE & Weight & $\begin{array}{l}\text { Hazard ratio } \\
\text { IV, fixed, } 95 \% \text { CI }\end{array}$ & \multicolumn{4}{|c|}{$\begin{array}{l}\text { Hazard ratio } \\
\text { IV, fixed, } 95 \% \text { CI }\end{array}$} \\
\hline Boorjian, 2008 & -0.186 & 0.332 & $27.2 \%$ & $0.83[0.43,1.59]$ & & - & & \\
\hline Xylinas, 2014 & -0.301 & 0.203 & $72.8 \%$ & $0.74[0.50,1.10]$ & & & & \\
\hline \multicolumn{3}{|l|}{ Total (95\% CI) } & $100.0 \%$ & $0.76[0.54,1.07]$ & & & & \\
\hline \multirow{2}{*}{\multicolumn{3}{|c|}{$\begin{array}{l}\text { Heterogeneity: chi }{ }^{2}=0.09, \mathrm{df}=1(P=0.77) ; l^{2}=0 \% \\
\text { Test for overall effect: } Z=1.56(P=0.12)\end{array}$}} & & 0.1 & 0.2 & 0.5 & 2 & 5 \\
\hline & & & & & \multicolumn{2}{|c|}{ Favours PD-L1+ } & Favo & PD-L1- \\
\hline
\end{tabular}

(c)

FIgURE 2: Forest plots of tumour cell PD-L1 expression predicted (a) OS, (b) CSS, and (c) DFS for all UC patients after cystectomy. PD-L1: programmed death-ligand 1; +/-: positive/negative; OS: overall survival; CSS: cancer-specific survival; DFS: disease-free survival; CI: confidence interval.

expression could serve as a prognostic biomarker for PFS but not $\mathrm{OS}$ in patients receiving anti-PD-1/PD-L1 immunotherapy.

Evidence suggested that UC was an immunogenic disease; in addition, presence of tumour-infiltrating lymphocytes (TILs) often correlated with immune response against the tumour and favorable clinical outcomes [29]. Aberrant expression of T-cell coregulatory molecule PD-L1 interacted with T-cell PD-1 that resulted in tumour-specific T-cell apoptosis, which might evade host immune surveillance, and was related with unfavorable outcomes in tumours [30]. Furthermore, PD-L1-positive expression has demonstrated a significant correlation with increased risk of disease progression and cancer death in various tumours [31-33]. Previously, two meta-analyses focused on PD-L1 and UC survival were reported. $\mathrm{Wu}$ et al. [34] indicated that PD-L1 status was related with worse 3 -year overall survival in UC, and Wang et al. [35] revealed that PD-L1 status could predict the clinical stage of UC. Our pooled results with HR value and 95\% CI raised a doubt and showed different results with them. We demonstrated that TC PD-L1 status was not correlated with the OS, CSS, or DFS in UC patients treated with cystectomy. However, for organ-confined UC, TC PD-L1 status could predict OS after cystectomy. Our findings were consistent with the published results of Boorjian et al. [4] and Xylinas et al. Increased tumour cell PD-L1 expression was related with advanced tumour stage, which could be an explanation for the predictive role of mortality in organ-confined but not local control tumours [4]. Of note, no study elevated the prognostic significance of immune cell PD-L1 status for UC patients receiving cystectomy, especially for early-stage tumours. Therefore, further trials are needed to explore whether PD-L1 expression in the immune cell has a prognostic role for UC patients who underwent cystectomy.

The recommended first-line therapy for metastatic UC is cisplatin-based chemotherapy, and nearly $50 \%$ of patients could respond to the treatment [36]. The improved prediction of clinical outcomes for advanced UC patients with platinum-based chemotherapy has recently attracted great interest [37, 38]. A recent RCT failed to demonstrate the p53 mutation either as a predictive biomarker of survival or as a response to adjuvant chemotherapy in UC patients who underwent RC [39]. PD-L1 status could predict postoperative outcomes in organ-confined UC patients and might provide better implications for the management of metastatic UC patients with chemotherapy. Our pooled results found that the expression of PD-L1 had no association with 


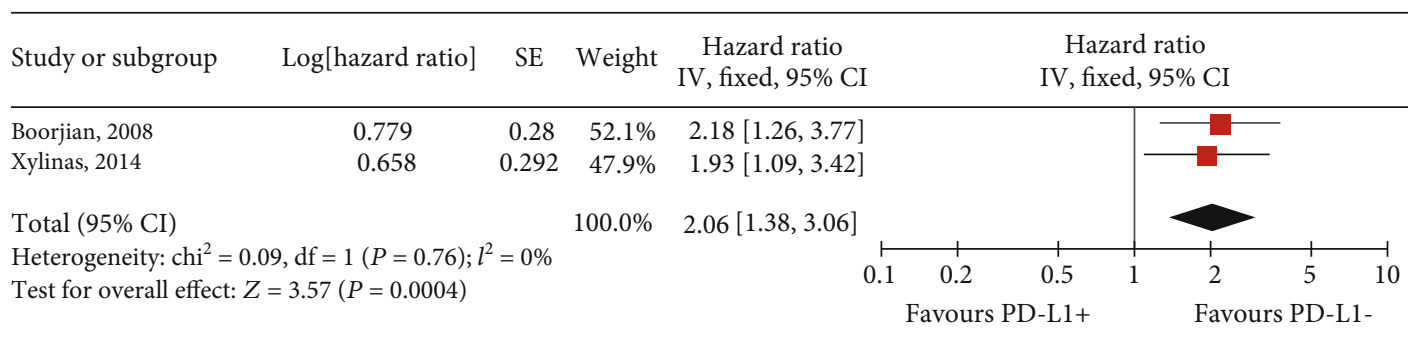

(a)

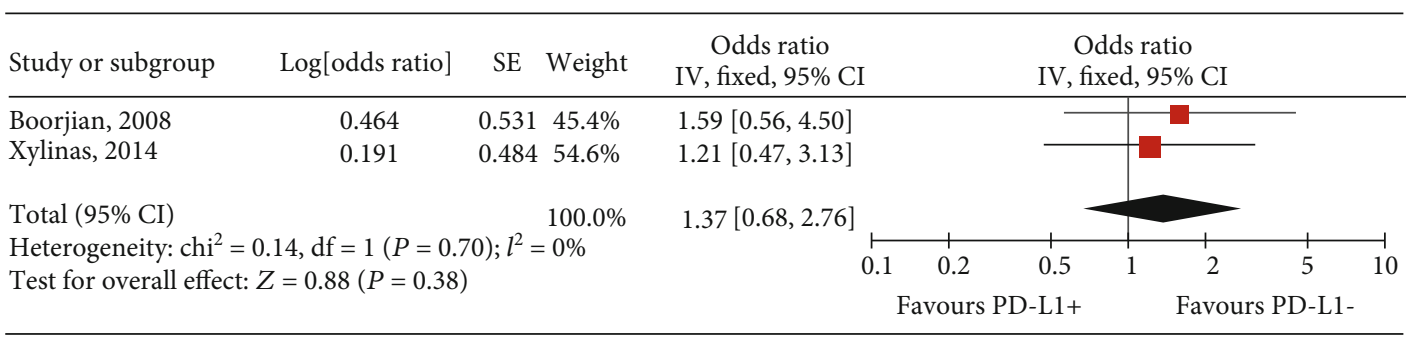

(b)

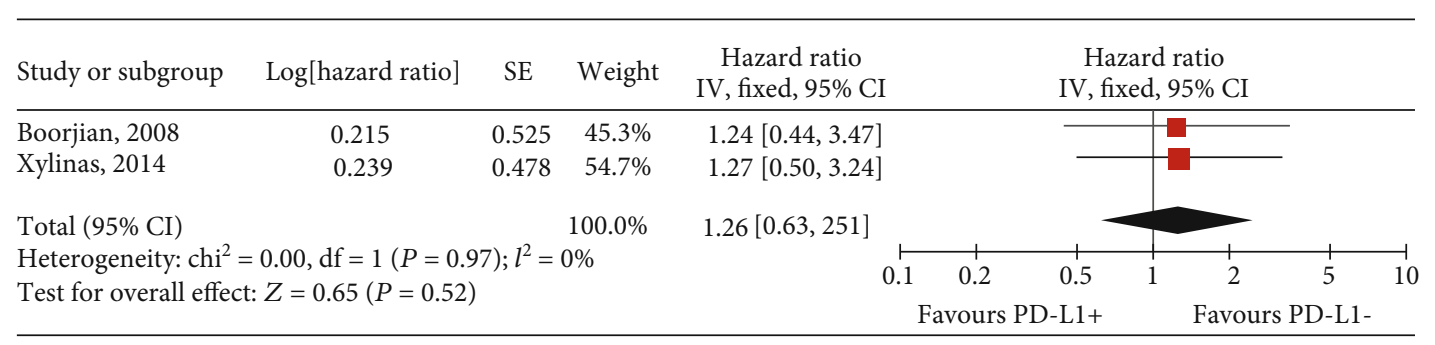

(c)

FIGURE 3: Forest plots of tumour cell PD-L1 expression for predicting (a) OS, (b) CSS, and (c) DFS for patients with organ-confined tumours after cystectomy. PD-L1: programmed death-ligand 1; +/-: positive/negative; OS: overall survival; CSS: cancer-specific survival; DFS: diseasefree survival; CI: confidence interval; IV: inverse variance; SE: standard error.

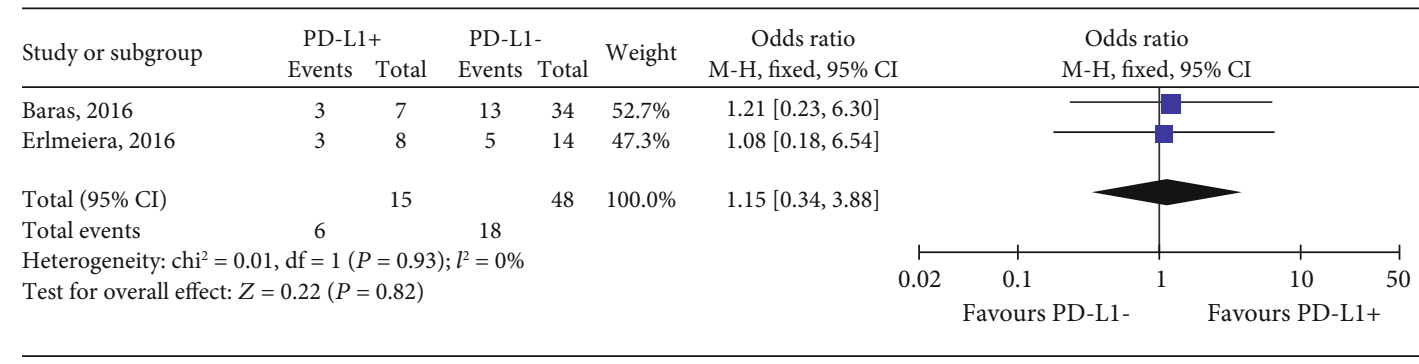

(a)

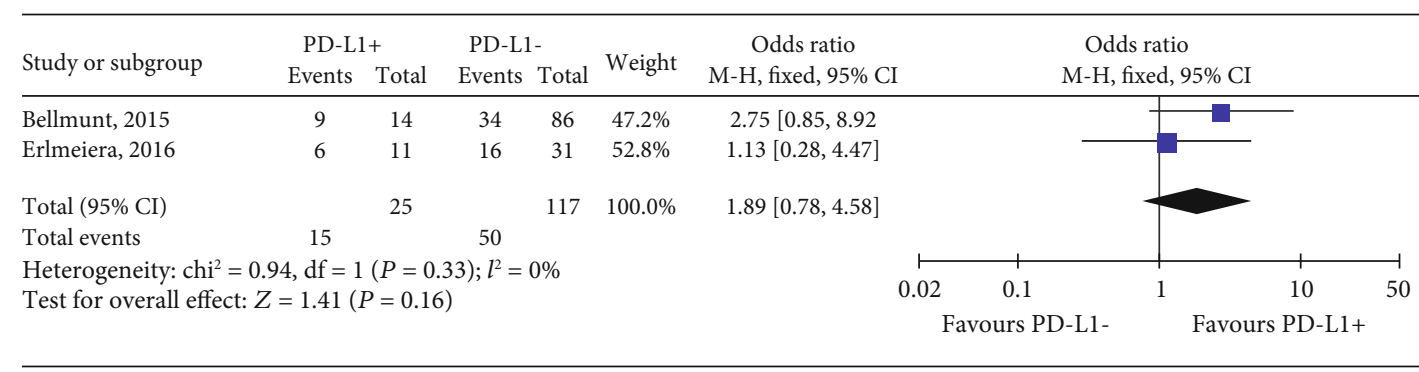

(b)

FIGURE 4: Forest plots of tumour cell PD-L1 status for predicting the (a) response and (b) prognosis to platinum-based chemotherapy in UC patients. PD-L1: programmed death-ligand 1; +/-: positive/negative; ORR: objective response rate; OS: overall survival; CI: confidence interval; M-H: Mantel-Hansel; SD: standard deviation. 


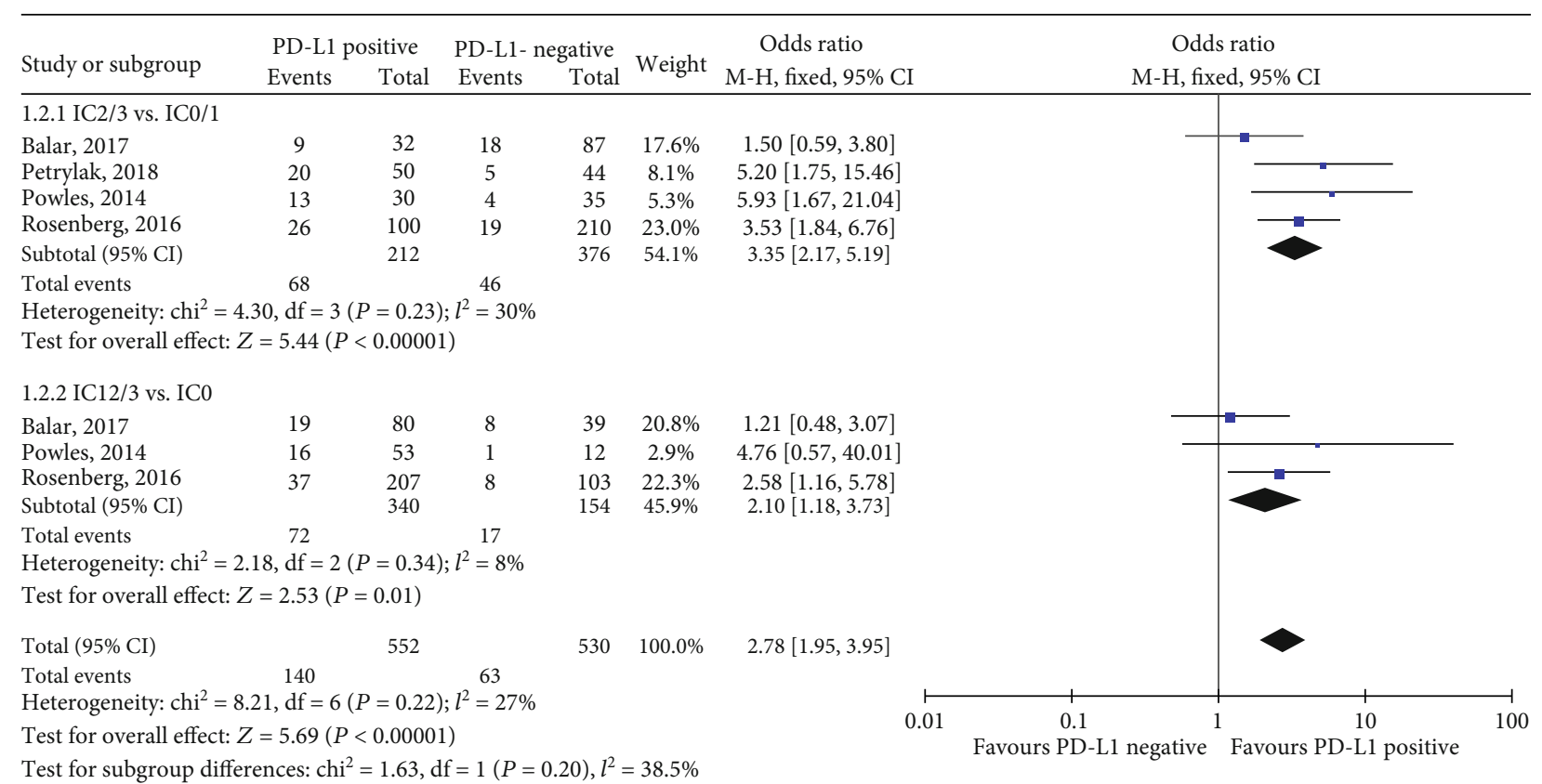

(a)

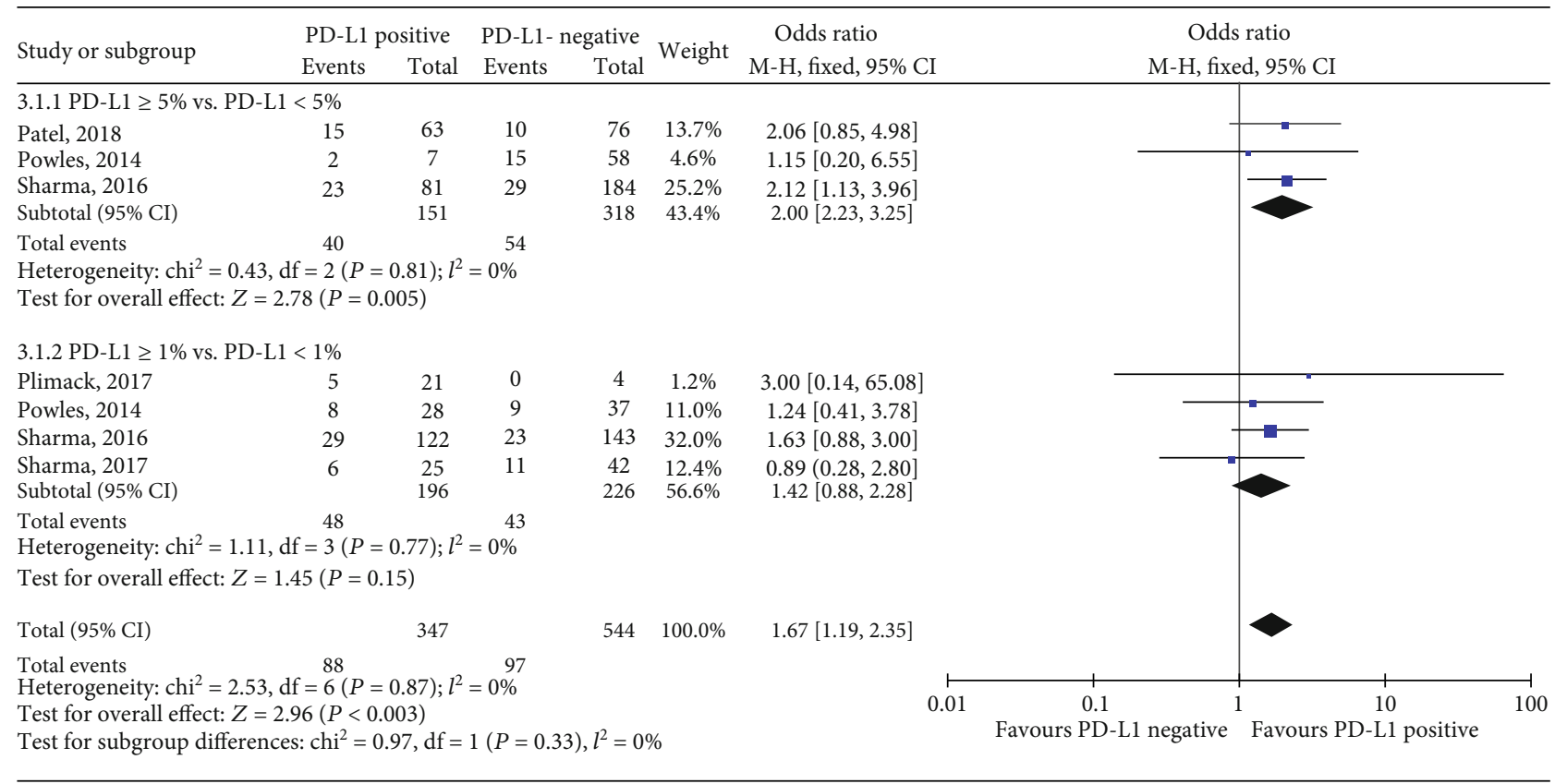

(b)

FIGURE 5: Forest plots of (a) immune cell and (b) tumour cell PD-L1 status with cut-off values of 5\% and $1 \%$ in predicting the response to antiPD-1/PD-L1 immunotherapy. PD-L1: programmed death-ligand 1; ORR: objective response rate; IC: immune cell; CI: confidence interval; M-H: Mantel-Hansel; SD: standard deviation.

prognostic or predictive benefit from platinum-based chemotherapy. It was similar with that of Tsao et al. [6], who performed a pooled analysis using three pivotal adjuvant chemotherapy trials, and found that TC PD-L1 had neither prognostic nor predictive value from adjuvant chemotherapy in NSCLC. We concluded the nonsignificant role of tumour cell PD-L1; however, further trials are needed to assess whether PD-L1 expression in the immune cell could be a prognosticator for UC patients with chemotherapy.
Cisplatin-based chemotherapies were associated with several substantial toxicities, and only $10 \%$ of participants responded to the second-line single-agent chemotherapy [6]. Immune checkpoint blockade is a promising new way to cancer therapy via the activation of therapeutic tumour immunity. It was reported that PD-1/PD-L1 inhibitors had regulatory efficacy for metastatic UC patients whose disease progressed following platinumbased chemotherapy [40]. Recently, Bellmunt and his 


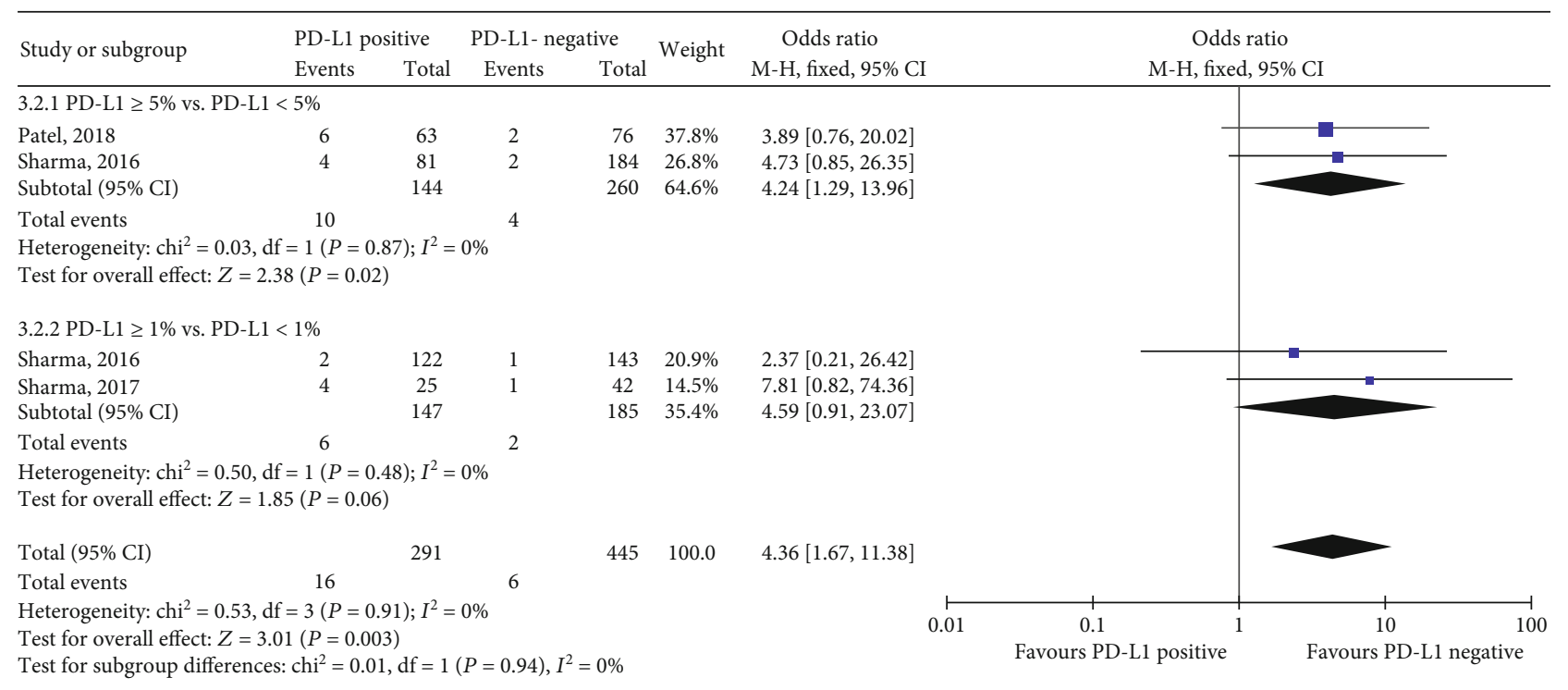

(a)

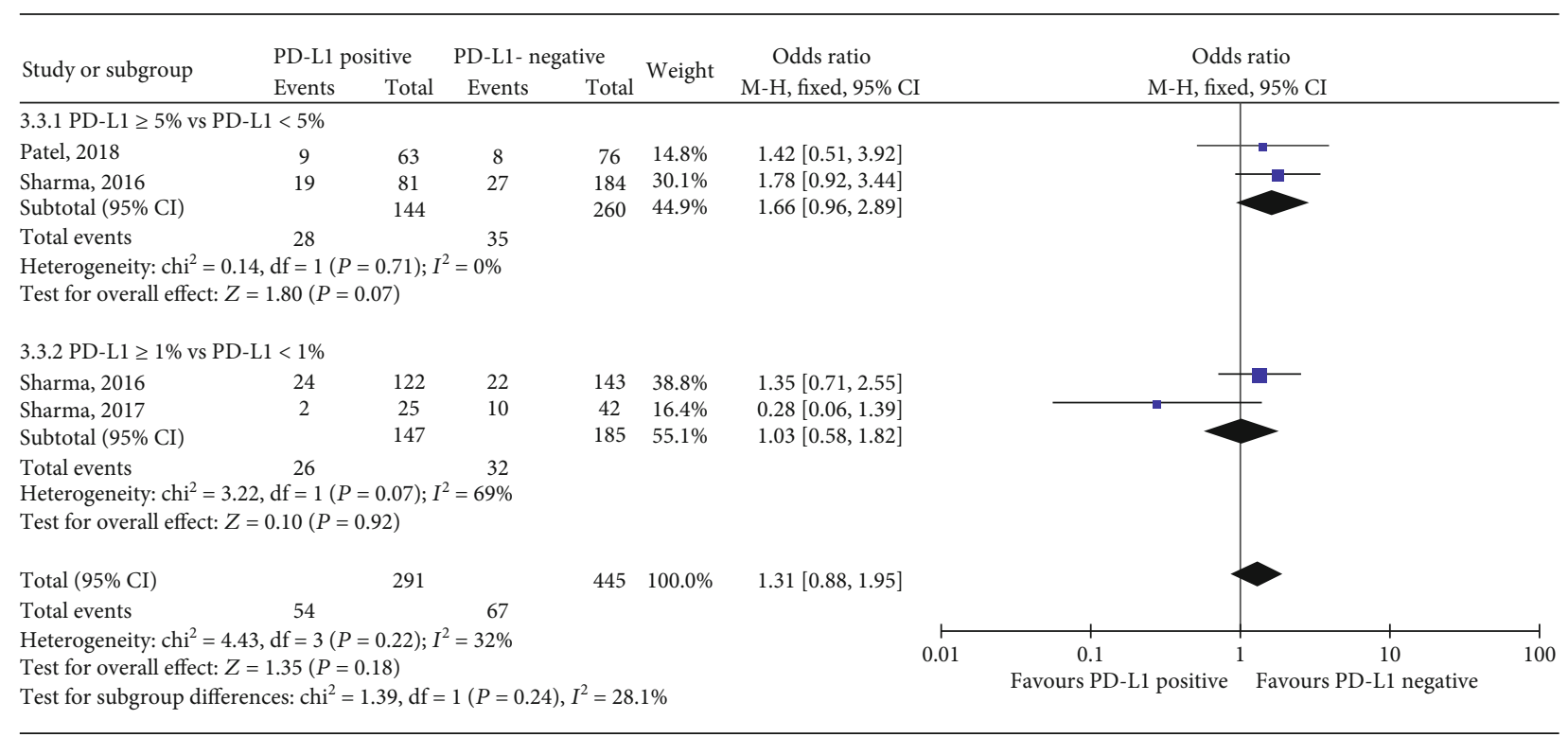

(b)

Figure 6: Continued. 


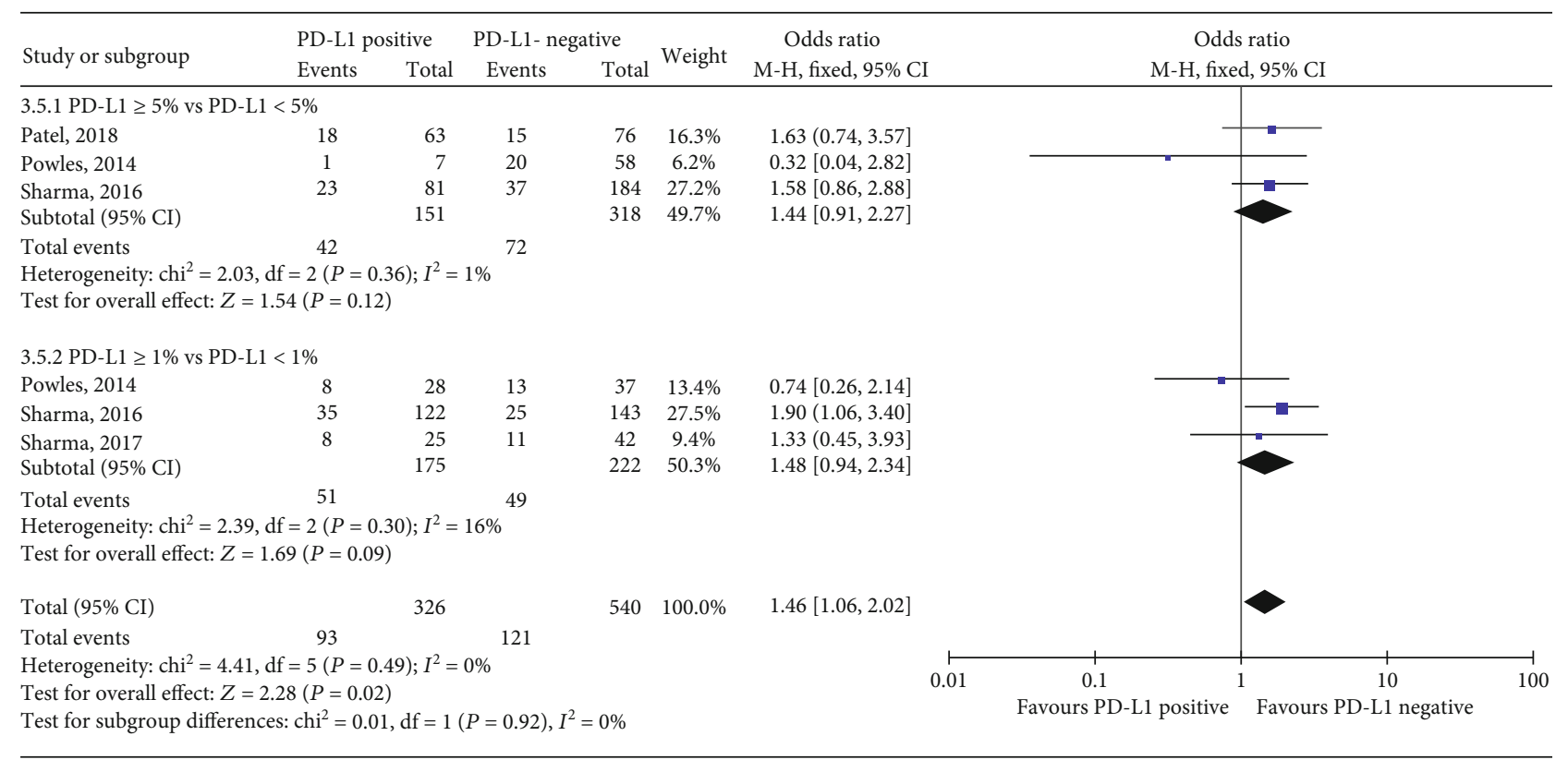

(c)

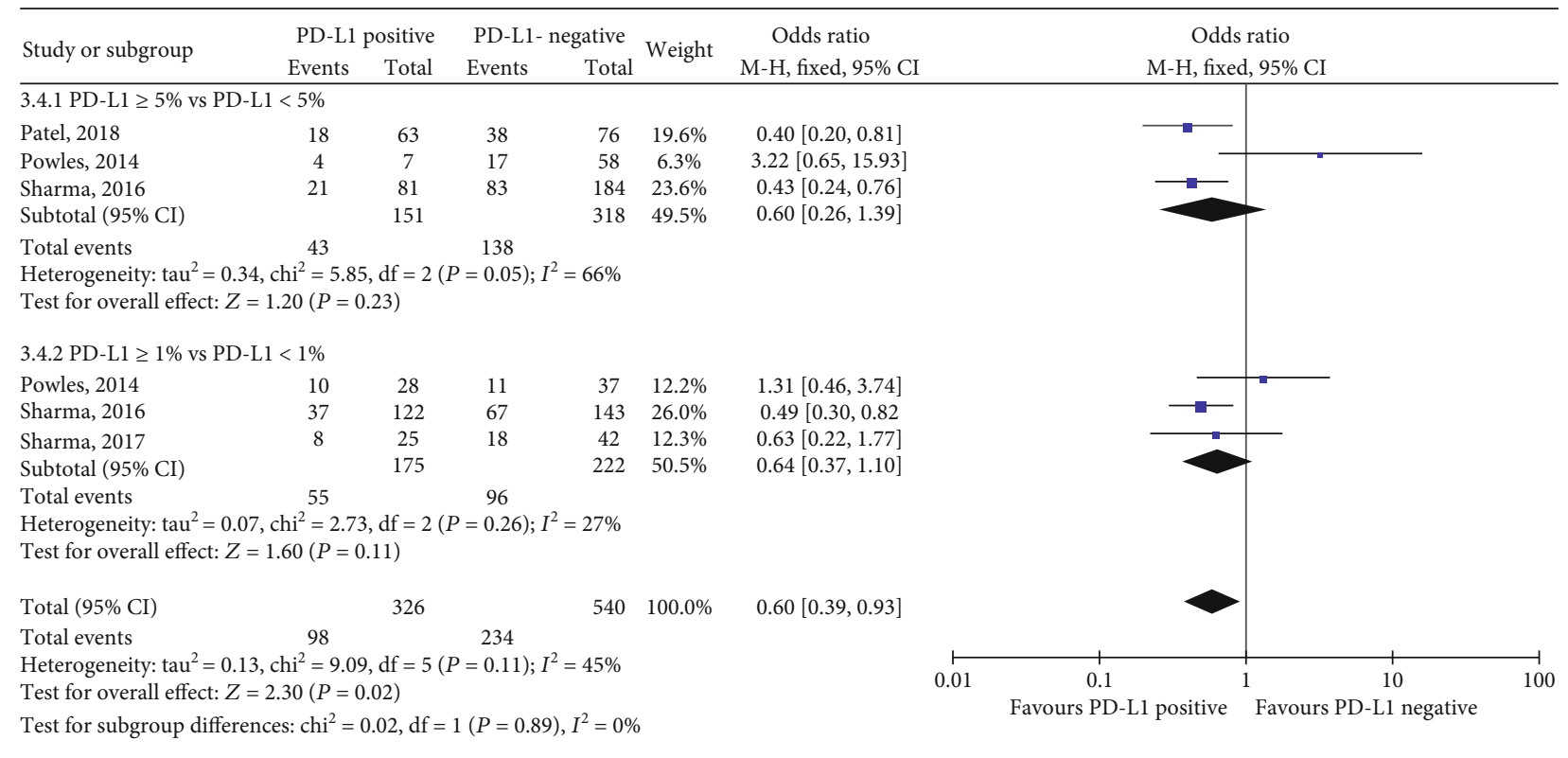

(d)

Figure 6: Forest plots of tumour cell PD-L1 status with cut-off values of $5 \%$ and $1 \%$ in predicting the (a) CR, (b) PR, (c) SD, and (d) PD to anti-PD-1/PD-L1 immunotherapy. PD-L1: programmed death-ligand 1; CR: completed response; PR: partial response; SD: stable disease; PD: progressive disease; CI: confidence interval; M-H: Mantel-Hansel; SD: standard deviation.

colleagues [7] reported that pembrolizumab (antibody against PD-1) could improve overall survival (by nearly 3 months) and have less therapy-related adverse events than chemotherapy for platinum-resistant advanced UC. Moreover, in a multicenter phase 1 and 2 cohort trial, nivolumab (one PD-1 inhibitor) raised a response in $24.4 \%$ of metastatic UC patients who had received previous chemotherapy without regard to TC PD-L1 expression $[13,25$, 26, 28]. And their findings also provided that PD-L1 status in immune cells was a promising predictor for selected UC patients treated with atezolizumab or nivolumab. Our results demonstrated that higher PD-L1 expression of TIICs but not TCs with a cut-off value of $5 \%$ showed better response to anti-PD-1/PD-L1 immunotherapy. When T-cells were activated by antigen, they produced several cytokines which could increase the expression of PD-L1 in adjacent tumour and immune cells [41]. PD-L1 expression in TIICs as well as TILs was tumour antigen-specific, and their response to the tumour could be an explanation for this. Balar et al. reported a median PFS of 4.1 months in IC2/3 patients which was longer than 2.1 months in IC1 patients and 2.6 months in IC0 patients. However, 


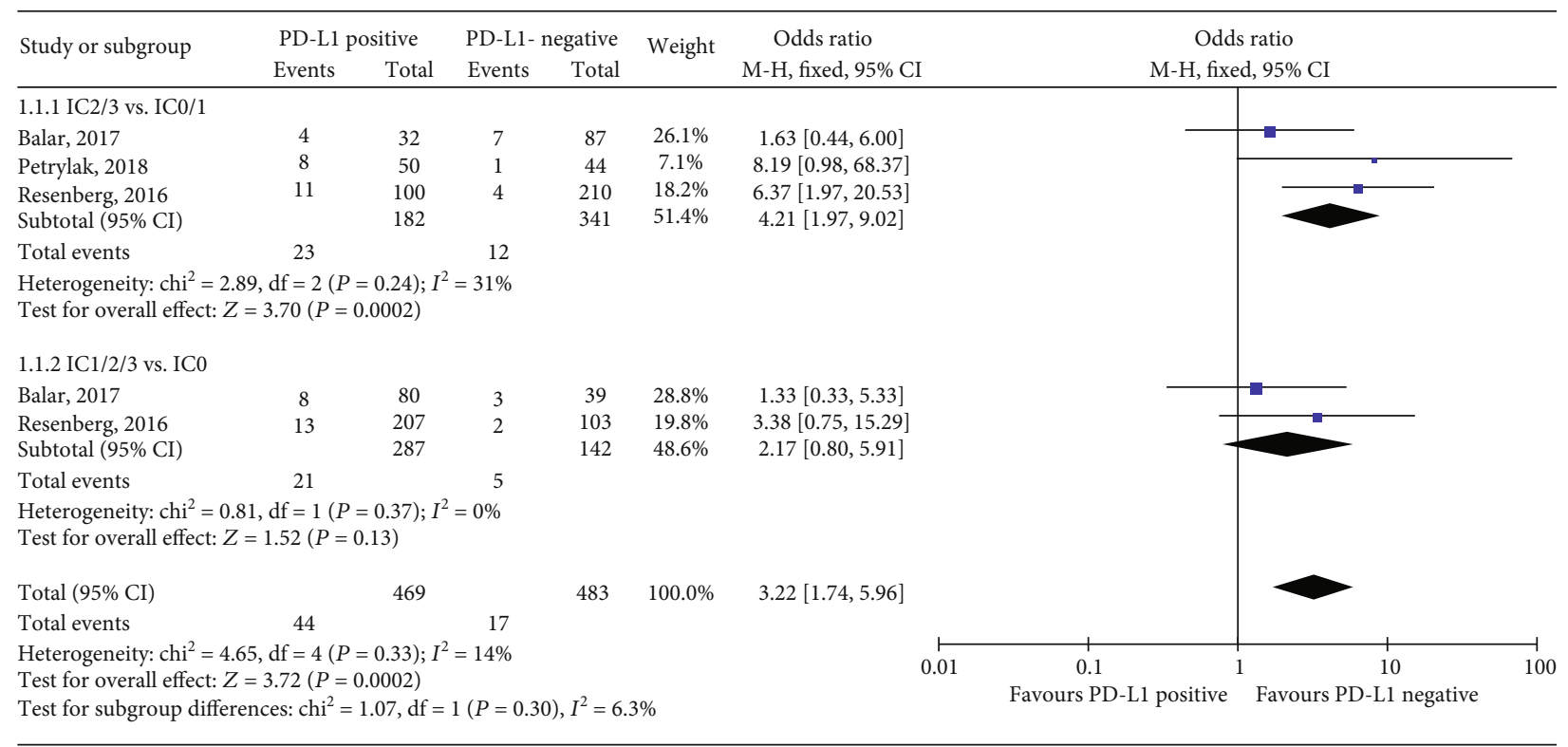

(a)

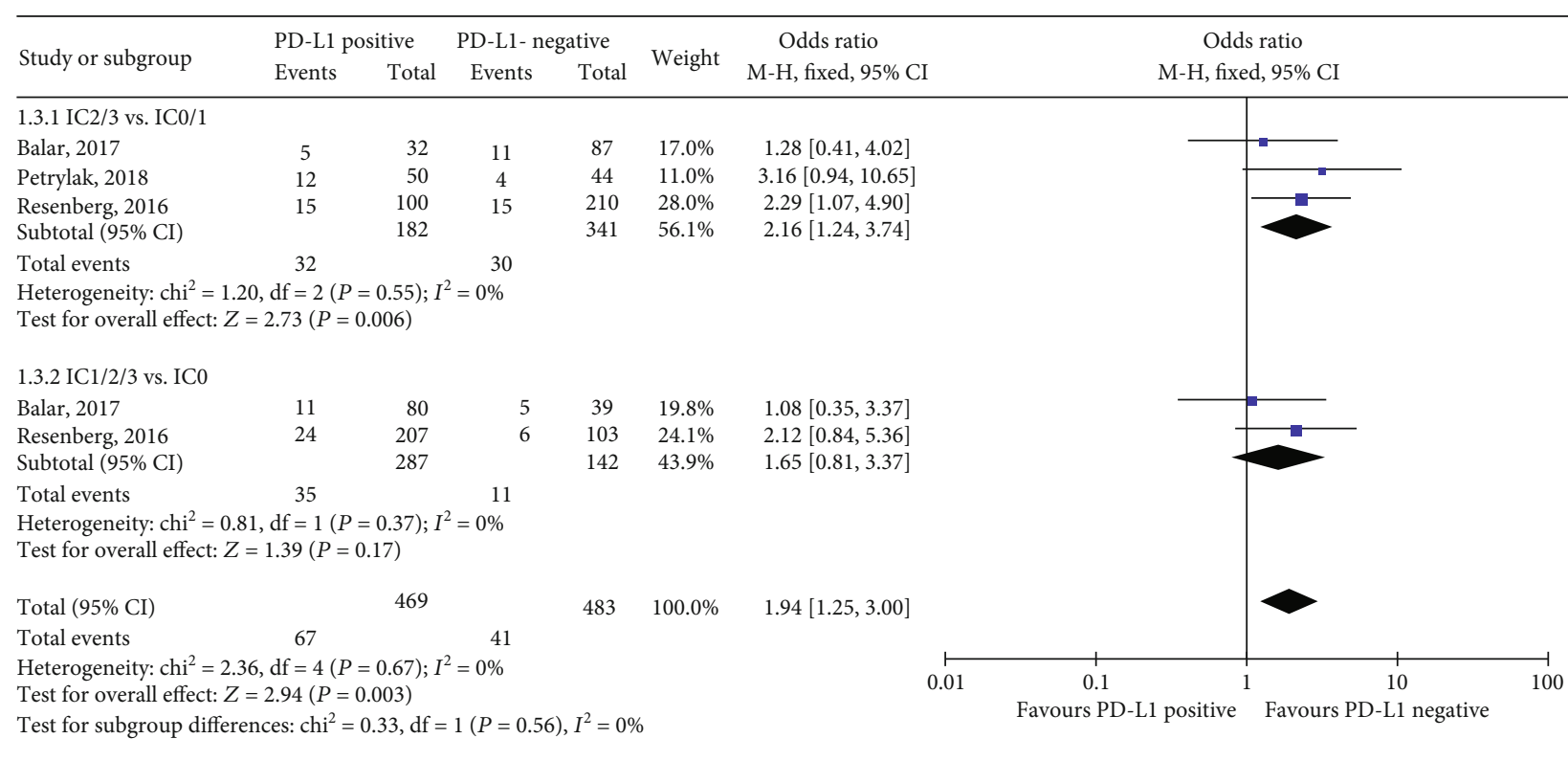

(b)

Figure 7: Continued. 


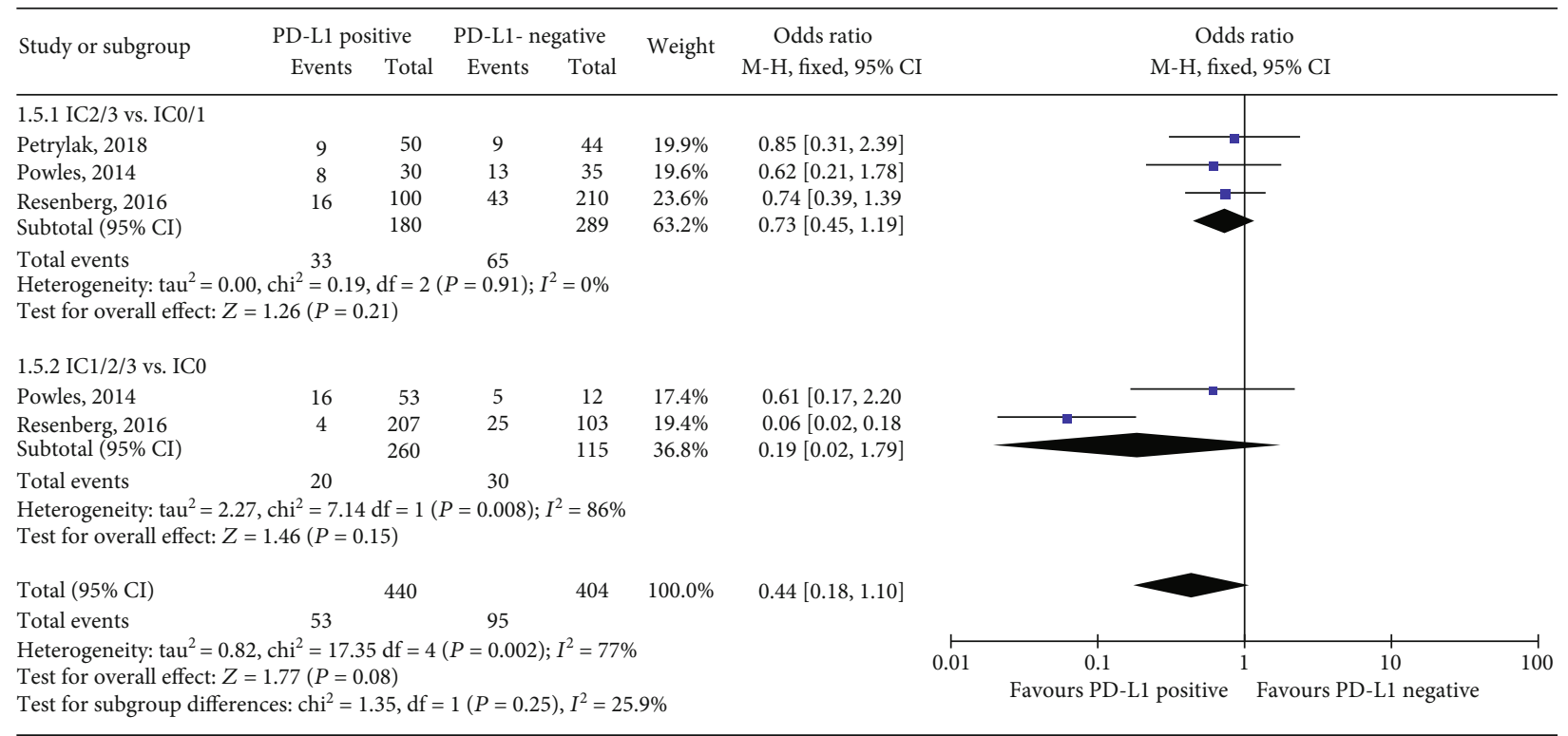

(c)

\begin{tabular}{|c|c|c|c|c|c|c|c|c|c|}
\hline \multirow{3}{*}{$\begin{array}{l}\text { Study or subgroup } \\
1.6 .1 \mathrm{IC} 2 / 3 \text { vs. IC } 0 / 1\end{array}$} & \multicolumn{2}{|c|}{ PD-L1 positive } & \multicolumn{2}{|c|}{ PD-L1- negative } & \multirow{2}{*}{ Weight } & \multirow{2}{*}{$\begin{array}{l}\text { Odds ratio } \\
\text { M-H, fixed, } 95 \% \text { CI }\end{array}$} & \multirow{2}{*}{\multicolumn{3}{|c|}{$\begin{array}{c}\text { Odds ratio } \\
\mathrm{M}-\mathrm{H} \text {, fixed, } 95 \% \mathrm{CI}\end{array}$}} \\
\hline & \multirow[t]{2}{*}{ Events } & \multirow[t]{2}{*}{ Total } & \multirow[t]{2}{*}{ Events } & \multirow[t]{2}{*}{ Total } & & & & & \\
\hline & & & & & & & & & \\
\hline Petrylak, 2018 & 17 & 50 & 24 & 44 & $15.8 \%$ & $0.43[0.19,0.99]$ & & & \\
\hline Powles, 2014 & 8 & 30 & 13 & 35 & $8.3 \%$ & $0.62[0.21,1.78]$ & & & \\
\hline Resenberg, 2016 & 44 & 100 & 115 & 210 & $39.0 \%$ & $0.65[0.40,1.05]$ & & & \\
\hline Subtotal $(95 \% \mathrm{CI})$ & & 180 & & 289 & $63.1 \%$ & $0.59[0.40,0.8$ & & & \\
\hline Total events & 69 & & 152 & & & & & & \\
\hline \multicolumn{10}{|c|}{$\begin{array}{l}\text { Heterogeneity: } \mathrm{chi}^{2}=0.72, \mathrm{df}=2(P=0.70) ; I^{2}=0 \% \\
\text { Test for overall effect: } Z=2.68(P=0.007)\end{array}$} \\
\hline \multicolumn{10}{|l|}{ 1.6.2 IC1/2/3 vs. IC0 } \\
\hline Powles, 2014 & 16 & 53 & 5 & 12 & $5.3 \%$ & $0.61[0.17,2.20]$ & & & \\
\hline Resenberg, 2016 & 107 & 207 & 52 & 103 & $31.5 \%$ & $1.05[0.65,1.68]$ & & & \\
\hline Subtotal $(95 \% \mathrm{CI})$ & & 260 & & 115 & $36.9 \%$ & $0.99[0.63,1.54]$ & & & \\
\hline Total events & 123 & & 57 & & & & & & \\
\hline \multicolumn{10}{|c|}{$\begin{array}{l}\text { Heterogeneity: chi }{ }^{2}=0.68 \mathrm{df}=1(P=0.43) ; I^{2}=0 \% \\
\text { Test for overall effect: } Z=0.07(P=0.95)\end{array}$} \\
\hline Total $(95 \% \mathrm{CI})$ & & 440 & & 404 & $100.0 \%$ & $0.74[0.55,0.98]$ & & & \\
\hline Total events & 192 & & 209 & & & & & & \\
\hline \multicolumn{6}{|c|}{ Heterogeneity: chi $^{2}=4.23 \mathrm{df}=4(P=0.38) ; I^{2}=5 \%$} & 0.01 & \multirow{2}{*}{ Favours PD-L1 positive } & 10 & 100 \\
\hline $\begin{array}{l}\text { Test for overall effect } \\
\text { Test for subgroup di }\end{array}$ & $\begin{array}{l}2.08(P= \\
\text { ces: } \text { chi }^{2}=\end{array}$ & 92, $\mathrm{df}=$ & $(P=0.0$ & $=65$. & & & & Favours PD-L1 negative & \\
\hline
\end{tabular}

(d)

Figure 7: Forest plots of immune cell PD-L1 status with cut-off values of $5 \%$ and $1 \%$ in predicting the (a) CR, (b) PR, (c) SD, and (d) PD to anti-PD-1/PD-L1 immunotherapy. PD-L1: programmed death-ligand 1; IC: immune cell; CR: completed response; PR: partial response; SD: stable disease; PD: progressive disease; CI: confidence interval; M-H: Mantel-Hansel; SD: standard deviation.

IC2/3 patients did not benefit from OS with a median of 15.9 months versus 19.1 months in IC0/1 patients [13]. Finally, our meta-analysis convinced us that immune cell PD-L1 status was useful as a prognostic biomarker for PFS but not OS in UC patients receiving anti-PD-1/PD-L1 immunotherapy. Our results supported that PD-L1 expression in immune cells might serve as a promising predictor for immune checkpoint blockade therapies in UC. Furthermore, PD-L1-negative patients also responded to the PD-1/PD-L1 blockade therapy, which highlighted the need for better response biomarkers for immunotherapies [13]. In addition, few studies with short-term follow-up resulted in lack of power for the analysis of positive IC PD-L1 status on survival benefit. Patients should be followed up to assess the response and other long-term survival.

Notably, several limitations still existed in our study. The main limitation of our meta-analysis reflected the drawbacks of the literatures concerning this topic; several available publications were out-of-date or enrolled a relatively small sample size, and only three RCTs were methodologically qualified. The second limitation was the different locations of $\mathrm{PD}-\mathrm{L} 1$ protein expressed; in most cases, they were only measured in tumour cells. However, there was no study reporting on immune cell PD-L1 status and 


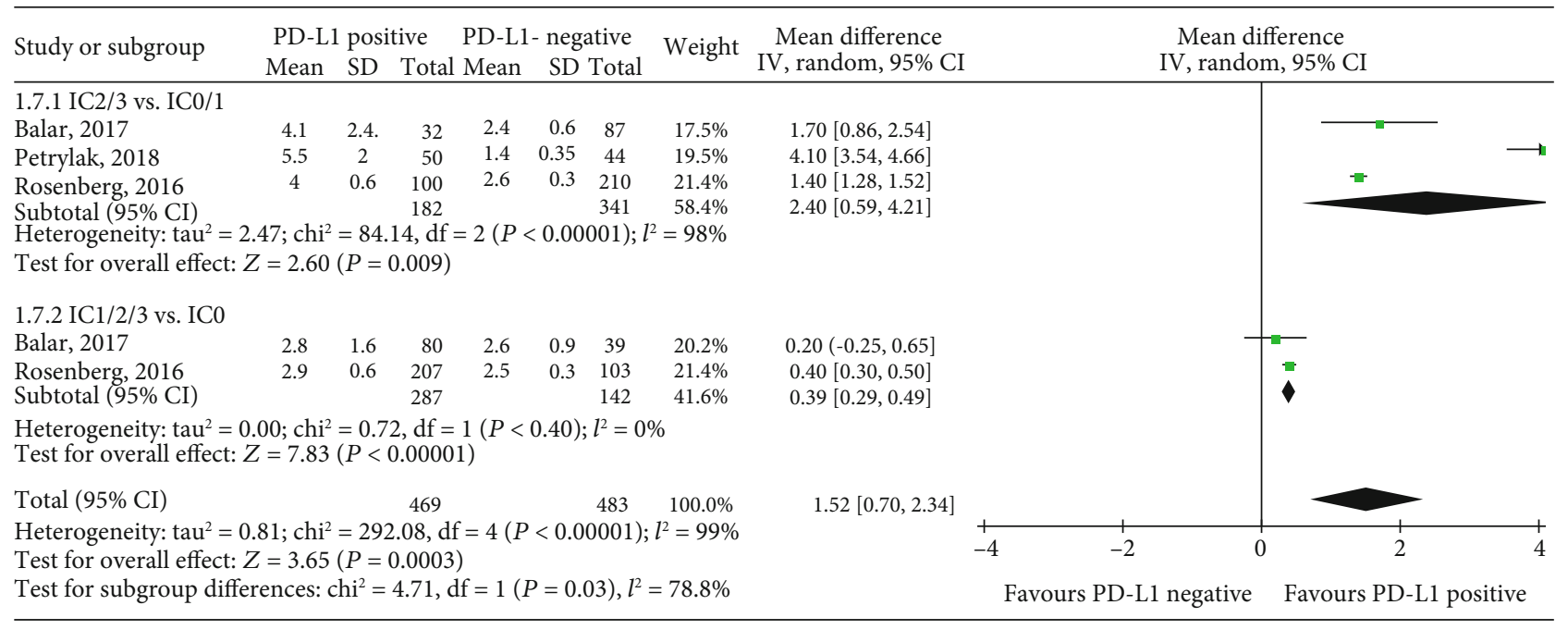

(a)

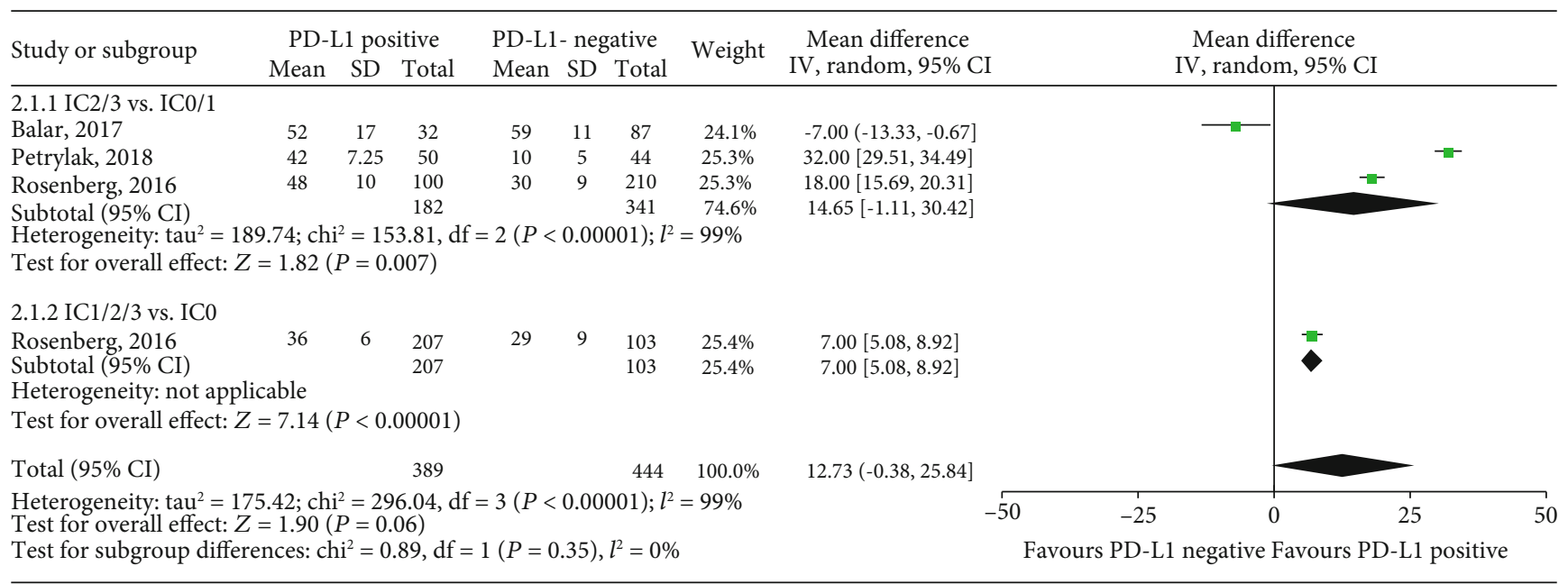

(b)

FIGURE 8: Forest plots of immune cell PD-L1 status with cut-off values of $5 \%$ and $1 \%$ in predicting the (a) PFS and (b) OS for UC patients with anti-PD-1/PD-L1 immunotherapy. PD-L1: programmed death-ligand 1; IC: immune cell; PFS: progression-free survival; OS: overall survival; CI: confidence interval; IV: inverse variance; SD: standard deviation.

survival after cystectomy, and only one study evaluated this in UC patients with chemotherapy. We could not pool the conclusion of immune cell PD-L1 status for predicting response and prognosis in patients treated with cystectomy or chemotherapy. The third limitation of our study was few comparative data for survival, leading to the lack of power for the analysis of survival benefit based on the limited studies with small sample sizes and short-term follow-up period. Patients should be followed up to assess the response and other long-term survival. Finally, other limits mainly included the different populations enrolled, the different drugs used, and the varying durations of treatment in the different studies included. Nevertheless, this systematic review offered a comprehensive overview of the predictive and prognostic significance of PD-L1 expression in UC patients after cystectomy, chemotherapy, or anti-PD1/PD-L1 immunotherapy for data extraction with a robust search strategy. Furthermore, we applied a rigorous inclu- sion/exclusion criterion to identify studies, different subgroup analyses, full outcomes of interest (ORR, CR, PR, $\mathrm{SD}, \mathrm{PD}, \mathrm{OS}, \mathrm{CSS}$, and DFS), and advanced meta-analysis using $\mathrm{HR}$ and corresponding 95\% CI for survival. Here, we provided up-to-date information of predictive and prognostic significance of PD-L1 in UC which was worthy for reference to the ongoing clinical trials.

Tumour cell PD-L1 expression showed significant association with advanced UC and could predict survival after cystectomy for organ-confined UC patients. Tumour cell PD-L1 status had no predictive or prognostic benefit from platinum-based chemotherapy. Higher PD-L1 expression of TIICs but not TCs with a cut-off value of $5 \%$ predicted better response to anti-PD-1/PD-L1 immunotherapy. TIIC PD-L1 status was useful as a prognostic biomarker for PFS but not OS in UC patients receiving anti-PD-1/PD-L1 immunotherapy. However, further RCTs with longer follow-up and a larger sample size should be conducted to verify whether 
the tumour immune cell PD-L1 as a biomarker has predictive and prognostic value in advanced UC patients treated with immune checkpoint inhibitors.

\section{Conflicts of Interest}

The authors have declared no competing interests.

\section{Authors' Contributions}

Haoran Liu and Tao Ye contribute equally to this work. The study concept and design were handled by TK and LRH; data extraction by TK and YT; data analysis by TK, LHR, YT, LP, $\mathrm{ZH}$, and WXL; manuscript preparation by TK and LRH; manuscript revision by TK, LHR, and YZQ; and study supervision by TK.

\section{Acknowledgments}

This project was supported by the National Natural Science Foundation of China (81270788, 81470935, 81370805, 81900645, and 81402087). The authors thank Kehua Jiang and Hua Xu for giving significant suggestions for the study design.

\section{References}

[1] J. Alfred Witjes, T. Lebret, E. M. Compérat et al., "Updated 2016 EAU guidelines on muscle-invasive and metastatic bladder cancer," European Urology, vol. 71, no. 3, pp. 462-475, 2017.

[2] K. Tang, H. Li, D. Xia et al., "Laparoscopic versus open radical cystectomy in bladder cancer: a systematic review and metaanalysis of comparative studies," PloS One, vol. 9, no. 5, article e95667, 2014.

[3] J. Bellmunt, S. A. Mullane, L. Werner et al., "Association of PD-L1 expression on tumor-infiltrating mononuclear cells and overall survival in patients with urothelial carcinoma," Annals of Oncology, vol. 26, no. 4, pp. 812-817, 2015.

[4] S. A. Boorjian, Y. Sheinin, P. L. Crispen et al., "T-cell coregulatory molecule expression in urothelial cell carcinoma: clinicopathologic correlations and association with survival," Clinical Cancer Research, vol. 14, no. 15, pp. 4800-4808, 2008.

[5] H. B. Grossman, R. B. Natale, C. M. Tangen et al., "Neoadjuvant chemotherapy plus cystectomy compared with cystectomy alone for locally advanced bladder cancer," The New England Journal of Medicine, vol. 349, no. 9, pp. 859-866, 2003.

[6] M.-S. Tsao, G. Le Teuff, F. A. Shepherd et al., "PD-L1 protein expression assessed by immunohistochemistry is neither prognostic nor predictive of benefit from adjuvant chemotherapy in resected non-small cell lung cancer," Annals of Oncology, vol. 28, no. 4, pp. 882-889, 2017.

[7] J. Bellmunt, R. de Wit, D. J. Vaughn et al., "Pembrolizumab as second-line therapy for advanced urothelial carcinoma," The New England Journal of Medicine, vol. 376, no. 11, pp. 10151026, 2017.

[8] R. S. Herbst, J. C. Soria, M. Kowanetz et al., "Predictive correlates of response to the anti-PD-L1 antibody MPDL3280A in cancer patients," Nature, vol. 515, no. 7528, pp. 563-567, 2014.
[9] Y. Iwai, M. Ishida, Y. Tanaka, T. Okazaki, T. Honjo, and N. Minato, "Involvement of PD-L1 on tumor cells in the escape from host immune system and tumor immunotherapy by PD-L1 blockade," Proceedings of the National Academy of Sciences of the United States of America, vol. 99, no. 19, pp. 12293-12297, 2002.

[10] S. M. Ansell, A. M. Lesokhin, I. Borrello et al., "PD-1 blockade with nivolumab in relapsed or refractory Hodgkin's lymphoma," The New England Journal of Medicine, vol. 372, no. 4, pp. 311-319, 2015.

[11] J. Brahmer, K. L. Reckamp, P. Baas et al., "Nivolumab versus docetaxel in advanced squamous-cell non-small-cell lung cancer," The New England Journal of Medicine, vol. 373, no. 2, pp. 123-135, 2015.

[12] C. Robert, G. V. Long, B. Brady et al., "Nivolumab in previously untreated melanoma without BRAF Mutation," The New England Journal of Medicine, vol. 372, no. 4, pp. 320330, 2015.

[13] A. V. Balar, M. D. Galsky, J. E. Rosenberg et al., “Atezolizumab as first-line treatment in cisplatin-ineligible patients with locally advanced and metastatic urothelial carcinoma: a single-arm, multicentre, phase 2 trial," The Lancet, vol. 389, no. 10064 , pp. 67-76, 2017.

[14] D. Moher, A. Liberati, J. Tetzlaff, D. G. Altman, and PRISMA Group, "Preferred reporting items for systematic reviews and meta-analyses: the PRISMA statement," International Journal of Surgery, vol. 8, no. 5, pp. 336-341, 2010.

[15] M. Borenstein, L. V. Hedges, J. P. Higgins, and H. R. Rothstein, "A basic introduction to fixed-effect and random-effects models for meta-analysis," Research Synthesis Methods, vol. 1, no. 2, pp. 97-111, 2010.

[16] J. Nakanishi, Y. Wada, K. Matsumoto, M. Azuma, K. Kikuchi, and S. Ueda, "Overexpression of B7-H1 (PD-L1) significantly associates with tumor grade and postoperative prognosis in human urothelial cancers," Cancer Immunology, Immunotherapy, vol. 56, no. 8, pp. 1173-1182, 2007.

[17] C. Massard, M. S. Gordon, S. Sharma et al., "Safety and efficacy of durvalumab (MEDI4736), an anti-programmed cell death ligand-1 immune checkpoint inhibitor, in patients with advanced urothelial bladder cancer," Journal of Clinical Oncology, vol. 34, no. 26, pp. 3119-3125, 2016.

[18] Y. Wang, Q. Zhuang, S. Zhou, Z. Hu, and R. Lan, "Costimulatory molecule B7-H1 on the immune escape of bladder cancer and its clinical significance," Journal of Huazhong University of Science and Technology [Medical Sciences], vol. 29, no. 1, pp. 77-79, 2009.

[19] E. Xylinas, B. D. Robinson, L. A. Kluth et al., "Association of Tcell co-regulatory protein expression with clinical outcomes following radical cystectomy for urothelial carcinoma of the bladder," European Journal of Surgical Oncology, vol. 40, no. 1, pp. 121-127, 2014.

[20] F. Erlmeier, A. K. Seitz, G. Hatzichristodoulou et al., “The role of PD-L1 expression and intratumoral lymphocytes in response to perioperative chemotherapy for urothelial carcinoma," Bladder Cancer, vol. 2, no. 4, pp. 425-432, 2016.

[21] A. S. Baras, C. Drake, J. J. Liu et al., "The ratio of CD8 to Treg tumor-infiltrating lymphocytes is associated with response to cisplatin-based neoadjuvant chemotherapy in patients with muscle invasive urothelial carcinoma of the bladder," Oncoimmunology, vol. 5, no. 5, article e1134412, 2016.

[22] M. R. Patel, J. Ellerton, J. R. Infante et al., “Avelumab in metastatic urothelial carcinoma after platinum failure (JAVELIN 
solid tumor): pooled results from two expansion cohorts of an open-label, phase 1 trial," The Lancet Oncology, vol. 19, no. 1, pp. 51-64, 2018.

[23] E. R. Plimack, J. Bellmunt, S. Gupta et al., "Safety and activity of pembrolizumab in patients with locally advanced or metastatic urothelial cancer (KEYNOTE-012): a non-randomised, open-label, phase 1b study," The Lancet Oncology, vol. 18, no. 2, pp. 212-220, 2017.

[24] T. Powles, J. P. Eder, G. D. Fine et al., "MPDL3280A (anti-PDL1) treatment leads to clinical activity in metastatic bladder cancer," Nature, vol. 515, no. 7528, pp. 558-562, 2014.

[25] P. Sharma, M. K. Callahan, P. Bono et al., "Nivolumab monotherapy in recurrent metastatic urothelial carcinoma (CheckMate 032): a multicentre, open-label, two-stage, multi-arm, phase 1/2 trial," The Lancet Oncology, vol. 17, no. 11, pp. 1590-1598, 2016.

[26] P. Sharma, M. Retz, A. Siefker-Radtke et al., "Nivolumab in metastatic urothelial carcinoma after platinum therapy (CheckMate 275): a multicentre, single-arm, phase 2 trial," The Lancet Oncology, vol. 18, no. 3, pp. 312-322, 2017.

[27] D. P. Petrylak, T. Powles, J. Bellmunt et al., “Atezolizumab (MPDL3280A) monotherapy for patients with metastatic urothelial cancer: long-term outcomes from a phase 1 study," JAMA Oncology, vol. 4, no. 4, pp. 537-544, 2018.

[28] J. E. Rosenberg, J. Hoffman-Censits, T. Powles et al., “Atezolizumab in patients with locally advanced and metastatic urothelial carcinoma who have progressed following treatment with platinum-based chemotherapy: a single-arm, multicentre, phase 2 trial," The Lancet, vol. 387, no. 10031, pp. 1909-1920, 2016.

[29] E. D. Carosella, G. Ploussard, J. LeMaoult, and F. Desgrandchamps, "A systematic review of immunotherapy in urologic cancer: evolving roles for targeting of CTLA-4, PD-1/PD-L1, and HLA-G," European Urology, vol. 68, no. 2, pp. 267-279, 2015.

[30] H. Dong, S. E. Strome, D. R. Salomao et al., "Tumor-associated B7-H1 promotes T-cell apoptosis: a potential mechanism of immune evasion," Nature Medicine, vol. 8, no. 8, pp. 793800, 2002.

[31] J. Calderaro, B. Rousseau, G. Amaddeo et al., "Programmed death ligand 1 expression in hepatocellular carcinoma: relationship with clinical and pathological features," Hepatology, vol. 64, no. 6, pp. 2038-2046, 2016.

[32] L. Danilova, H. Wang, J. Sunshine et al., "Association of PD1/PD-L axis expression with cytolytic activity, mutational load, and prognosis in melanoma and other solid tumors," Proceedings of the National Academy of Sciences of the United States of America, vol. 113, no. 48, pp. E7769-E7777, 2016.

[33] Y. Masugi, R. Nishihara, J. Yang et al., "Tumour CD274 (PD-L1) expression and T cells in colorectal cancer," Gut, vol. 66, no. 8, pp. 1463-1473, 2017.

[34] P. Wu, D. Wu, L. Li, Y. Chai, and J. Huang, "PD-L1 and survival in solid tumors: a meta-analysis," PloS One, vol. 10, no. 6, article e0131403, 2015.

[35] Y. U. Wang, A. N. Liu, and S. H. Zhao, "Association between B7-H1 expression and bladder cancer: a meta-analysis," Genetics and Molecular Research, vol. 14, no. 1, pp. 1277-1286, 2015.

[36] H. von der Maase, S. W. Hansen, J. T. Roberts et al., "Gemcitabine and cisplatin versus methotrexate, vinblastine, doxorubicin, and cisplatin in advanced or metastatic bladder cancer: results of a large, randomized, multinational, multicenter, phase III study," Journal of Clinical Oncology, vol. 18, no. 17, pp. 3068-3077, 2000.

[37] F. H. Groenendijk, J. de Jong, E. E. Fransen van de Putte et al., "ERBB2 mutations characterize a subgroup of muscle-invasive bladder cancers with excellent response to neoadjuvant chemotherapy," European Urology, vol. 69, no. 3, pp. 384-388, 2016.

[38] E. R. Plimack, R. L. Dunbrack, T. A. Brennan et al., "Defects in DNA repair genes predict response to neoadjuvant cisplatinbased chemotherapy in muscle-invasive bladder cancer," European Urology, vol. 68, no. 6, pp. 959-967, 2015.

[39] W. M. Stadler, S. P. Lerner, S. Groshen et al., "Phase III study of molecularly targeted adjuvant therapy in locally advanced urothelial cancer of the bladder based on p53 status," Journal of Clinical Oncology, vol. 29, no. 25, pp. 3443-3449, 2011.

[40] J. Bellmunt, T. Powles, and N. J. Vogelzang, "A review on the evolution of PD-1/PD-L1 immunotherapy for bladder cancer: the future is now," Cancer Treatment Reviews, vol. 54, pp. 5867, 2017.

[41] T. Bald, J. Landsberg, D. Lopez-Ramos et al., "Immune cellpoor melanomas benefit from PD-1 blockade after targeted type I IFN activation," Cancer Discovery, vol. 4, no. 6, pp. 674-687, 2014. 